\title{
Article
}

\section{D Printed Cobalt-Chromium-Molybdenum Porous Superalloy with Superior Antiviral Activity}

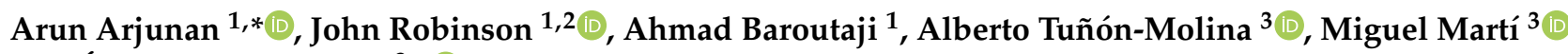 \\ and Ángel Serrano-Aroca ${ }^{3, *}$ (D)
}

1 Centre for Engineering Innovation and Research, Additive Manufacturing of Functional Materials (AMFM) Research Group, Faculty of Science and Engineering, Telford Innovation Campus, University of Wolverhampton, Telford TF2 9NT, UK; J.Robinson12@wlv.ac.uk (J.R.); A.Baroutaj@@wlv.ac.uk (A.B.)

2 Additive Analytics Ltd., Stirchley Road, Telford TF3 1EB, UK

3 Biomaterials and Bioengineering Lab, Centro de Investigación Traslacional San Alberto Magno, Universidad Católica de Valencia San Vicente Mártir, c/Guillem de Castro 94, 46001 Valencia, Spain; alberto.tunon@ucv.es (A.T.-M.); miguel.marti@ucv.es (M.M.)

* Correspondence: A.Arjunan@wlv.ac.uk (A.A.); angel.serrano@ucv.es (Á.S.-A.)

Citation: Arjunan, A.; Robinson, J.; Baroutaji, A.; Tuñón-Molina, A.; Martí, M.; Serrano-Aroca, Á. 3D Printed Cobalt-ChromiumMolybdenum Porous Superalloy with Superior Antiviral Activity. Int. J. Mol Sci. 2021, 22, 12721. https://doi.org/ 10.3390/ijms222312721

Academic Editor: Young-Jin Kim

Received: 15 October 2021

Accepted: 22 November 2021

Published: 24 November 2021

Publisher's Note: MDPI stays neutral with regard to jurisdictional claims in published maps and institutional affiliations.

Copyright: (c) 2021 by the authors. Licensee MDPI, Basel, Switzerland. This article is an open access article distributed under the terms and conditions of the Creative Commons Attribution (CC BY) license (https:// creativecommons.org/licenses/by/ $4.0 /)$.

\begin{abstract}
COVID-19 pandemic and associated supply-chain disruptions emphasise the requirement for antimicrobial materials for on-demand manufacturing. Besides aerosol transmission, SARS-CoV-2 is also propagated through contact with virus-contaminated surfaces. As such, the development of effective biofunctional materials that can inactivate SARS-CoV-2 is critical for pandemic preparedness. Such materials will enable the rational development of antiviral devices with prolonged serviceability, reducing the environmental burden of disposable alternatives. This research reveals the novel use of Laser Powder Bed Fusion (LPBF) to 3D print porous Cobalt-Chromium-Molybdenum (Co-Cr-Mo) superalloy with potent antiviral activity (100\% viral inactivation in $30 \mathrm{~min})$. The porous material was rationally conceived using a multi-objective surrogate model featuring track thickness $\left(t_{t}\right)$ and pore diameter $\left(\phi_{d}\right)$ as responses. The regression analysis found the most significant parameters for Co-Cr-Mo track formation to be the interaction effects of scanning rate $\left(V_{s}\right)$ and laser power $\left(P_{l}\right)$ in the order $P_{l} V_{s}>V_{s}>P_{l}$. Contrastively, the pore diameter was found to be primarily driven by the hatch spacing $\left(S_{h}\right)$. The study is the first to demonstrate the superior antiviral properties of 3D printed Co-Cr-Mo superalloy against an enveloped virus used as biosafe viral model of SARS-CoV-2. The material significantly outperforms the viral inactivation time of other broadly used antiviral metals such as copper and silver, as the material's viral inactivation time was from $5 \mathrm{~h}$ to $30 \mathrm{~min}$. As such, the study goes beyond the current state-of-the-art in antiviral alloys to provide extra protection to combat the SARS-CoV-2 viral spread. The evolving nature of the COVID-19 pandemic brings new and unpredictable challenges where on-demand 3D printing of antiviral materials can achieve rapid solutions while reducing the environmental impact of disposable devices.
\end{abstract}

Keywords: SARS-CoV-2; COVID-19; Cobalt; Chromium; Molybdenum; superalloy; 3D printing; antiviral; Laser Powder Bed Fusion

\section{Introduction}

Severe Acute Respiratory Syndrome Coronavirus 2 (SARS-CoV-2) is the third human coronavirus [1-4] that is much more contagious than SARS-CoV and MERS-CoV [5-12]. Its rapid transmission rate has provoked the current coronavirus disease (COVID-19) pandemic. SARS-CoV-2 is a highly pathogenic enveloped positive-sense single-stranded RNA virus [13-15] that belongs to the Baltimore group IV [16]. This global life-threatening situation needs the development of new antimicrobial approaches that could treat or prevent COVID-19 infections [17-22]. In this regard, non-woven fabrics are currently used for the fabrication of infection prevention clothing, such as face masks, caps, scrubs, shirts, trousers, disposable gowns, overalls, hoods, aprons, and shoe covers. These infection prevention 
tools are needed, especially in hospitals during surgical operations, in microbiological and biomedical biosafety laboratories, and face masks should be worn by most citizens as a demonstrated prevention tool in the current COVID-19 pandemic [23]. Nevertheless, these items of clothing for infection prevention are produced with materials that do not possess antimicrobial properties, and some progress has been achieved thus far in the development of antimicrobial prevention fabrics [24].

Many disinfectants such as household bleach, hand soap solution, ethanol, povidoneiodine, chloroxylenol, chlorhexidine and benzalkonium chloride have shown potent antiviral activity against SARS-CoV-2 so far [25]. Thus, non-woven fabrics for the fabrication of face masks and face shields have been treated with benzalkonium chloride to produce antimicrobial infection prevention tools [26,27]. Very recently, non-woven fabrics have been coated with solidified hand soap to produce antimicrobial face masks capable of inactivating SARS-CoV-2 in one minute of contact [28]. Other authors have produced next generation infection prevention materials using other antimicrobial agents such as antimicrobial polymers, salts, carbon nanomaterials, metals or metal oxides [24,29-31]. However, very few studies about the use of natural and biodegradable compounds such as cranberry extracts have been reported [24].

Cranberry extracts have shown antiviral activity against other enveloped viruses such as the herpes simplex virus type 1 (HSV-1) and type 2 (HSV-2) due to the presence of antimicrobial A-type proanthocyanidins (PACs) that provoke alterations of their envelope glycoproteins. However, although HSV-1 and HSV-2 belong to a different Baltimore group I [16] than SARS-CoV-2 because they are double-stranded DNA viruses, they are also enveloped viruses like SARS-CoV-2. A cranberry extract has also exhibit antiviral activity against influenza virus (IFV) [32]. IFV is a negative-sense single-stranded RNA virus that belongs to the Baltimore group V [16]. However, it is also enveloped like HSV-1 and HSV-2. Therefore, since it seems that the PACs present in cranberry extracts effectively interact with the envelope glycoproteins achieving viral inhibition, we hypothesize here that a commercial non-woven fabric treated with two different commercial extracts produced with different cranberries will show antiviral activity against the enveloped SARS-CoV-2 and phi 6 viruses. The phage phi 6 is also an enveloped double-stranded RNA virus (group III of the Baltimore classification [16]) that can be used as surrogate of SARS-CoV-2 and other enveloped viruses such as influenza due to biosafety reasons [26]. Furthermore, atypical viral pneumonia is associated with SARS-CoV-2 infection $[2,33]$ that can increase its risk by co-infection with Gram-positive bacteria [34-37], including clinically relevant antibioticresistant strains. Additionally, bacterial resistance to pneumonia treatments is increasing at an alarming rate [38,39]. Since the PACs present in cranberry extracts are well-known for their antibacterial properties against Gram-negative Escherichia coli [40] and antifungal activity against Candida albicans [41], we hypothesize here also that the two non-woven fabrics dip-coated with cranberry extracts will show also antibacterial activity against two Gram-positive multidrug-resistant bacteria, the methichillin-resistant Staphylococcus aureus (MRSA) and the methichillin-resistant Staphylococcus epidermidis (MRSE).

The existence and evolution of SARS-CoV-2 coronavirus variants are spreading more effectively than earlier ones [42,43] due to its evolutionary advantage over SARS-CoV primarily in enhanced host receptor binding [44]. According to Sun and Ostrikov [45], this gives the virus a longer-lasting ability to retain activity on diverse surfaces. As such the lessons so far dealing with SARS-CoV-2 transmission suggests that the new developments of antiviral materials are critical in establishing pandemic preparedness $[45,46]$.

The development of effective materials with antiviral capacity is critical in the development of reusable protective devices such as mask filters, high-efficiency particulate air filters (HEPA) and other antiviral devices [47]. Antiviral portable HEPA filters, air purifiers and aerosol decontaminants are critical also for hospital isolation wards and temporary anterooms [48]. Currently, contaminated devices such as masks and filters are disposable under strict protocol, which is often ignored and possess a serious risk of secondary contamination [49]. A recent study by Maclntyre et al. [50] confirmed that even 
decontamination of reusable masks through washing still offer the probability of infection; further highlighting the need for antiviral materials. Careless disposal of masks is another issue that is resulting in a potential source of microplastic pollution [51] and environmental damage threatening aquatic and animal habitats [52-54].

The development of antiviral face mask that contain porous filters or antiviral face shields made of antiviral materials capable of inactivating SARS-CoV-2 is an effective strategy to provide extra protection against the COVID-19 transmission [26-28,55] and produce reusable devices to reduce environmental impacts [54,56]. The COVID-19 pandemic has also highlighted the potential for supply chain disruptions causing shortages of essential supplies including PPE, swabs, and ventilators [57-59]. As such, there is a requirement for on-demand and onsite manufacturing of antiviral materials suitable for a range of applications. Digital manufacturing techniques such as additive manufacturing (3D printing) demonstrated in this study offers significant potential making on-demand and onsite fabrication of antiviral devices accessible [58,60]. Additive manufacturing (AM) is transforming medical supplies by allowing personalisation and onsite fabrication enhancing resilience against supply chain disruption [61-64]. This subsequently results in rapid development and deployment of potential solutions which is critical when it comes to pandemic preparedness [65-67]. Nevertheless, achieving this requires the development of antimicrobial materials [68-70] and processes that can be additively manufactured without the requirement for complex pre/post-processing as demonstrated in this study.

According to Doremalen et al. [71], aerosol and surface transmission of SARS-CoV-2 facilitates infection as the virus can persist for extended periods in a range of common materials as listed in Table 1. Kumar et al. [72] highlight that not many studies have examined the effectiveness of metallic materials against SARS-CoV-2 leading to data scarcity for decision making. Generally, the long duration required for inactivation of coronaviruses by metals such as silver $(\mathrm{Ag})$ and copper $(\mathrm{Cu})$ indicates that they might be ineffective when rapid disinfection is required [73,74]. Furthermore, the high cost of these materials is also prohibitive when it comes to their mass adoption as an effective antiviral material.

Table 1. Duration of coronavirus persistence in different materials.

\begin{tabular}{ccc}
\hline Material & Duration & Ref. \\
\hline Aerosol & $1.2 \mathrm{~h}$ & Doremalen et al. [71] \\
Glass & 4 days & Duan et al. [75] \\
Plastic & $<5$ days & Chan et al. [76] \\
PVC & $4-9$ days & Duan et al. [75] and Rabenau et al. [77] \\
Paper & $1-5$ days & Lai et al. [78] and Duan et al. [75] \\
Steel & 3 days & Doremalen et al. [71] \\
Wood & $4-5$ days & Duan et al. [75] and Kampf et al. [79] \\
Ceramics & 5 days & Aydogdu et al. [80] \\
Silicon rubber & 5 days & Shidham et al. [81] and Aydogdu et al. [80] \\
Copper & $4-5 \mathrm{~h}$ & Hutasoit et al. [82] and Doremalen et al. [71] \\
Silver & $4-5 \mathrm{~h}$ & Kumar et al. [72] and Balagna et al. [83] \\
\hline
\end{tabular}

When it comes to 3D printed metallic materials, only $\mathrm{Cu}$ coating deposited using cold spray have reported $99.2 \%$ virus inactivation at $5 \mathrm{~h}$ [82]. Antiviral properties of $\mathrm{Cu}$ against SARS-CoV-2 are increasingly being documented at around 4-5 h [73,84]. Other than Ag and $\mathrm{Cu}$ based compositions, studies on the antiviral properties of alternative alloys against SARS-CoV-2 are yet to be reported. As such, the current state-of-art inactivation times for metallic alloys is around $4-5 \mathrm{~h}$ against SARS-CoV- 2 which demands composition with superior antiviral efficacy where this study contributes.

According to Hatamie et al. [85], cobalt (Co) is an essential trace element that is significantly less toxic in comparison to non-essential metals. Studies on the antimicrobial properties of Co complexes [86] have shown effectiveness against seven microbial strains namely Bacillus subtilis, Escherichia coli, Klebsiella pneumoniae, Salmonella enterica, Shigella flexneri, Proteus vulgaris and Staphylococcus aureus. Recently, Kota et al. [87] showed Co-Cr to be ef- 
fective in suppressing S. aureus and P. acnes proliferation both in vitro and in vivo infection models. Overall, Co-based alloys seem to offer a broad-spectrum antimicrobial possibility making them worthy candidates to explore for potential antiviral activity. Currently, literature on the antiviral properties of Co-based alloys is scarce let alone their performance against SARS-CoV-2.

This research, therefore, is the first step towards drastically improving the state-ofthe-art antiviral alloys against SARS-CoV-2 at the interface of 3D printing and surrogate modelling. The research reveals the first $\mathrm{Co}-\mathrm{Cr}$-Mo porous material with superior antiviral activity that can be 3D printed on-demand where the innovation pipeline is kept open. The study is directed towards a process-structure-property relationship where both the material and its processing parameters collectively inform an optimum functional architecture. The influence of the LPBF 3D printing process on the structure-property relationship at the sub-micrometre is also analysed to make the digital and on-demand fabrication of the antiviral material accessible and easily scalable.

Overall, the development, analysis, and optimisation Co-Cr-Mo LPBF porous superalloy that feature high antiviral activity against an enveloped virus such as SARS-CoV-2 are demonstrated for the first time. The effect of LPBF process parameters on the characteristics of the porous architecture such as the thickness of the laser melted track $\left(t_{t}\right)$ and pore diameter $\left(\phi_{d}\right)$ are also carried out. This was done with the help of a surrogate model that features laser power $\left(P_{l}\right)$, hatch spacing $\left(S_{h}\right)$ and scanning rate $\left(V_{s}\right)$ as LPBF process parameters. The surrogate model was validated and subsequently used for parametric analysis which characterised the order of influence and interaction effects between the process parameters and the resulting printed $\mathrm{Co}-\mathrm{Cr}$-Mo architecture.

\section{Results and Discussion}

\subsection{Morphology LPBF Samples}

Although Co-Cr-Mo-based superalloys are suitable for LPBF [88-90], no studies have demonstrated a rationally conceived process informed by porosity at a track thicknesses below $300 \mu \mathrm{m}$. Before identifying the influence of the process parameters on the fabricated samples, the working limits of the LPBF process variables were assessed. This was a critical step as the porosity of $\mathrm{Co}-\mathrm{Cr}-\mathrm{Mo}$ is dictated by the process parameters as opposed to geometry.

The Co-Cr-Mo porous test specimens were printed for all LPBF parametric combinations informed by the rationally conceived surrogate model. The samples were removed from the build plate and analysed under SEM to characterise their porosity. The resulting morphologies of LPBF Co-Cr-Mo porous architecture informed by randomised parametric combinations are shown in Figure 1. The parametric combinations of laser power $\left(P_{l}\right)$, scan speed $\left(V_{s}\right)$, and hatch spacing $\left(S_{h}\right)$ are sufficient for raising the required energy density at the powder bed for printing Co-Cr-Mo at varying porosity. The entire parametric range selected for the training matrix was found to be suitable to fully laser melt $\mathrm{Co}-\mathrm{Cr}-\mathrm{Mo}$ showing stable and continuous track formation.

As the pore size reduced significantly as shown in Figure $1 \mathrm{j}, \mathrm{k}$, some inconsistency in porosity and spatter contamination can be observed. This is due to the high energy density at the centre of the laser spot causing a recoil pressure at the melt pool while other parts of the melt pool are solidifying, which result in the expulsion of the molten material. The spattered metal subsequently cool down forming particles of varying sizes depending on the duration of the condensation process. These spatter formations are not unique to Co-Cr-Mo and are widely observed in a range of materials processed using powder bed fusion as summarised by Young et al. [91]. Although some spatters are observed, these are not extensive and can be seen to not obstruct the overall porous architecture being generated. 


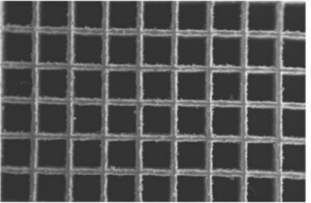

(a)

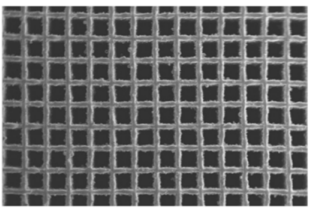

(e)

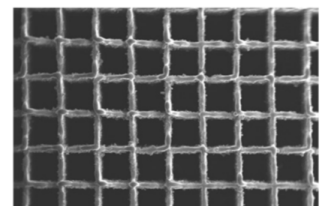

(i)

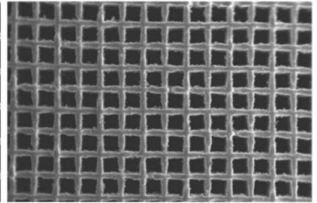

(b)

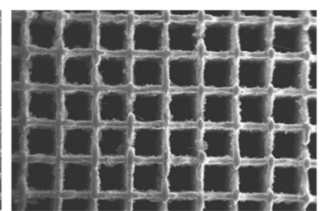

(f)

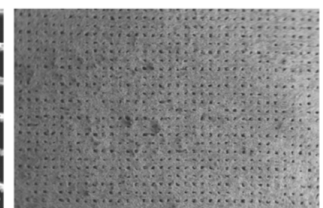

(j)

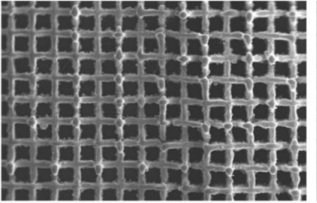

(c)

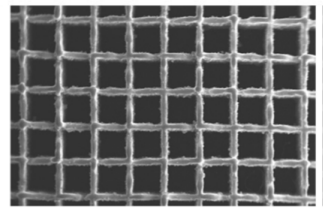

(g)

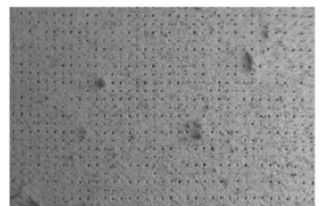

(k)

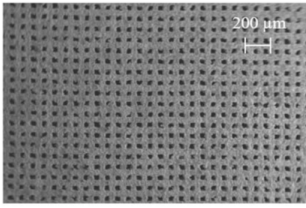

(d)

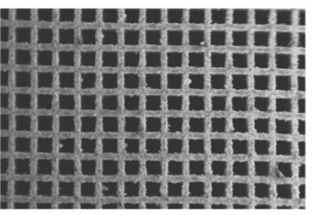

(h)

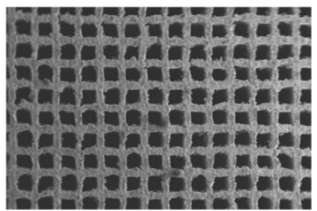

(l)

Figure 1. SEM data of additively manufactured Co-Cr-Mo informed by randomised process parameter $\left(S_{h}\right.$ is the hatch spacing, $V_{s}$ is the scanning rate and $P_{l}$ is the laser power) combinations that were subsequently used to train the surrogate model used to generate optimum $\mathrm{Co}-\mathrm{Cr}-\mathrm{Mo}$ microporous superalloy showing (a) $S_{h}=0.60 \mathrm{~mm}, V_{s}=900 \mathrm{~mm} / \mathrm{s}, P_{l}=85 \mathrm{~W}$, (b) $S_{h}=0.37 \mathrm{~mm}$, $V_{s}=900 \mathrm{~mm} / \mathrm{s}, P_{l}=110 \mathrm{~W}$, (c) $S_{h}=0.37 \mathrm{~mm}, V_{s}=1025 \mathrm{~mm} / \mathrm{s}, P_{l}=135 \mathrm{~W}$, (d) $S_{h}=0.14 \mathrm{~mm}$, $V_{s}=900 \mathrm{~mm} / \mathrm{s}, P_{l}=85 \mathrm{~W}$, (e) $S_{h}=0.37 \mathrm{~mm}, V_{s}=1025 \mathrm{~mm} / \mathrm{s}, P_{l}=85 \mathrm{~W}$, (f) $S_{h}=0.60 \mathrm{~mm}$, $V_{s}=900 \mathrm{~mm} / \mathrm{s}, P_{l}=135 \mathrm{~W},(\mathrm{~g}) S_{h}=0.37 \mathrm{~mm}, V_{s}=775 \mathrm{~mm} / \mathrm{s}, P_{l}=85 \mathrm{~W}$, (h) $S_{h}=0.60 \mathrm{~mm}$, $V_{s}=775 \mathrm{~mm} / \mathrm{s}, P_{l}=110 \mathrm{~W}$, (i) $S_{h}=0.60 \mathrm{~mm}, V_{s}=1025 \mathrm{~mm} / \mathrm{s}, P_{l}=110 \mathrm{~W}$, (j) $S_{h}=0.14 \mathrm{~mm}$, $V_{s}=1025 \mathrm{~mm} / \mathrm{s}, P_{l}=110 \mathrm{~W},(\mathbf{k}) S_{h}=0.14 \mathrm{~mm}, V_{s}=775 \mathrm{~mm} / \mathrm{s}, P_{l}=110 \mathrm{~W}$, (l) $S_{h}=0.37 \mathrm{~mm}$, $V_{\mathrm{s}}=775 \mathrm{~mm} / \mathrm{s}, P_{l}=135 \mathrm{~W}$.

Although the printed samples established the suitability of conceiving process-induced porosity, the ideal combination of the process parameters that will result in an optimum porous construct to maximise surface contact is required. However, the parameters should ensure that the generated $\phi_{d}$ is not so low making the powder removal impossible. To establish such an optimum parametric combination, the order of influence of the process parameters on the resulting track thickness and pore size is required. This gives rise to a multi-objective optimisation problem which was established using a surrogate model.

\subsection{Surrogate Model}

\subsubsection{Training Matrix and Regression Analysis}

Controlling the three parameters for the formation of targeted track width, and pore size requires establishing a process-property relationship. The attempt is to fabricate $\mathrm{Co}-$ Cr-Mo architecture that features the thinnest track width and smallest possible distance between adjacent tracks while preserving porosity. Achieving this requires characterising both the interaction effects and order of influence of the LPBF process variables on the printed Co-Cr-Mo porous material.

To achieve the process-property relationship, a randomised BBD training matrix is generated as shown in Table 2 informed by the factors identified in Table 8 . Keeping the layer thickness constant, three remaining primary LPBF process parameters that can vary the energy density at the powder bed were used as the variable factors. Consideration was also given when selecting the maximum and minimum limits of these process parameters to make sure sufficient energy density was available for $\mathrm{Co}-\mathrm{Cr}$-Mo melt pool generation.

Test prints were carried out in Co-Cr-Mo for all parametric combinations dictated by the matrix. Their characteristic results measured using SEM for track thickness and pore diameter are listed in Table 2 . The results of the analysis were used to identify LPBF 
process parameters that had the most and least significance on the responses of interest. While the ideal combination of LPBF process parameters for fully dense $\mathrm{Co}-\mathrm{Cr}-\mathrm{Mo}$ is being increasingly documented [92-94], the literature is rather scarce when it comes to processing porosity and the fabrication of tracks with thickness below $300 \mu \mathrm{m}$.

Table 2. Co-Cr-Mo surrogate model training matrix showing randomised parameters and the measured responses. $S_{h}$ is the hatch spacing, $V_{s}$ is the scanning rate, $P_{l}$ is the laser power, $t_{t}$ is the track thickness and $\phi_{d}$ is the pore diameter.

\begin{tabular}{ccccc}
\hline & Variable Factors & & \multicolumn{2}{c}{ Responses $(\boldsymbol{\mu m})$} \\
\hline $\boldsymbol{A}=\boldsymbol{S}_{\boldsymbol{h}}(\mathbf{m m})$ & $\boldsymbol{B}=\boldsymbol{V}_{\boldsymbol{s}}(\mathbf{m m} / \mathbf{s})$ & $\boldsymbol{C}_{\mathbf{m}} \boldsymbol{P}_{\boldsymbol{l}} \mathbf{( W )}$ & $\boldsymbol{t}_{\boldsymbol{t}}$ & $\boldsymbol{\phi}_{\boldsymbol{d}}$ \\
\hline 0.60 & 900 & 85 & 97 & 502 \\
0.37 & 900 & 110 & 118 & 262 \\
0.37 & 1025 & 135 & 111 & 272 \\
0.37 & 900 & 110 & 118 & 262 \\
0.37 & 900 & 110 & 118 & 262 \\
0.14 & 900 & 85 & 97 & 62 \\
0.37 & 1025 & 135 & 94 & 264 \\
0.60 & 900 & 85 & 128 & 479 \\
0.37 & 775 & 110 & 99 & 275 \\
0.60 & 775 & 110 & 113 & 474 \\
0.60 & 1025 & 110 & 78 & 494 \\
0.37 & 900 & 110 & 118 & 262 \\
0.37 & 900 & 110 & 78 & 262 \\
0.14 & 1025 & 110 & 113 & 65 \\
0.14 & 775 & 135 & 136 & 53 \\
0.37 & 775 & &
\end{tabular}

The regression analysis of the training data from Table 2 based on best-fit indicators revealed that the thickness of Co-Cr-Mo track has a quadratic relationship with the LPBF process parameters as listed in Equation (1). The pore size or the linear distance between two adjacent tracks however was found to follow a linear relationship as listed in Equation (2). A quadratic dependency when it comes to track thickness indicates strong interaction effects between the LPBF process parameters considered. This means that specifying each of the LPBF process parameters require a critical understanding of the linking parameters and their interaction effects to accurately control the resulting $t_{t}$.

$$
\phi_{d}=-86.22+937.02 S_{h}+0.04 V_{s}-0.28 P_{l}
$$

$t_{t}=-566+111.96 S_{h}+1.45 V_{s}+0.39 P_{l}-2.8 e^{-15} S_{h} V_{s}+0.17 S_{h} P_{l}-1.6 e^{-3} V_{s} P_{l}-198.48 S_{h}{ }^{2}-7.68 e^{-4} V_{s}{ }^{2}+6.4 e^{-3} P_{l}{ }^{2}$

\subsubsection{Model Accuracy}

The accuracy of the surrogate models was evaluated using the analysis of variance (ANOVA) technique where the significant model terms are as summarised in Table 3 . The relevant accuracy indicators include the probability ( $p$-value), coefficient of determination $R^{2}$, Adjusted $R^{2}$, and Adequate precision. It can be seen that all models exhibit high F-values and very low p-values confirming that the models are significant. In statistical terms, surrogate models with a p-value less than 0.05 and an adequate precision ratio greater than 4 signifies an accurate model [95]. A closer to unity $R^{2}$ and Adj- $R^{2}$ also indicates that the surrogate model is accurate for all the responses analysed. 
Table 3. Analysis of variance showing the accuracy of the surrogate model developed.

\begin{tabular}{cccccc}
\hline \multirow{2}{*}{ Model } & \multirow{2}{*}{ F-Value } & \multirow{2}{*}{$\boldsymbol{p}$-Value } & \multicolumn{3}{c}{ Statistical Measurements } \\
\cline { 4 - 6 } & & & $\mathbf{R}^{\mathbf{2}}$ & Adj-R $^{\mathbf{2}}$ & Adeq-Precision \\
\hline$t_{t}$ & 12.60 & 0.003 & 0.9498 & 0.8744 & 12.7989 \\
$\phi_{d}$ & 1602.67 & $<0.0001$ & 0.9975 & 0.9969 & 108.7482 \\
\hline
\end{tabular}

The relationship between actual responses and those based on the surrogate model are shown in Figure 2. As can be seen, the residuals are close to the predicted results which validate the accuracy of the surrogate model. Overall, the ANOVA demonstrates that all the models developed in this study are suitable for making valid predictions. This means that Equations (1) and (2) adequately characterise the relationship between the laser power, scanning rate, and hatch spacing and to that of the resulting properties of porous $\mathrm{Co}-\mathrm{Cr}-\mathrm{Mo}$. This means that the surrogate model can be used to analyse the interaction effects between the process parameters and to identify their optimum combinations to print an optimum porous architecture.

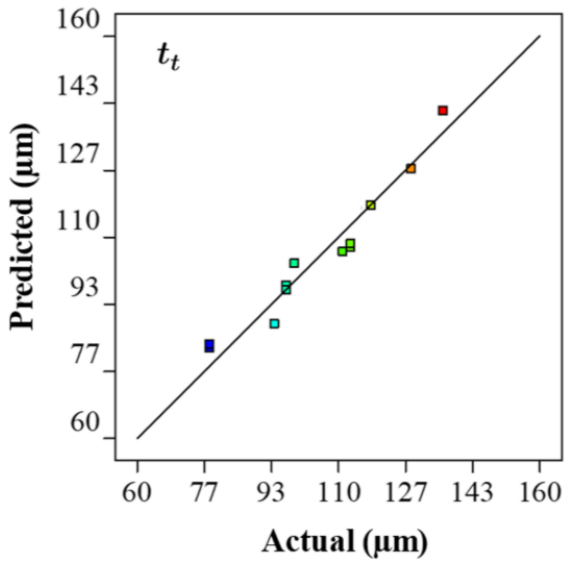

(a)

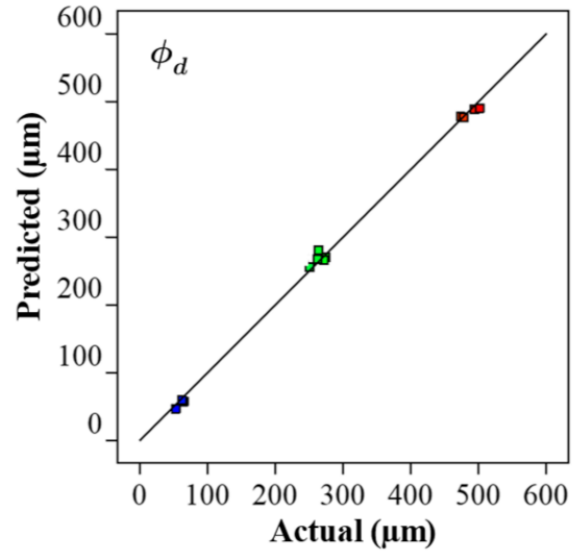

(b)

Figure 2. Comparison of experimentally measured and predicted values for the parametrically developed Co-Cr-Mo architecture demonstrating the accuracy of the surrogate model for (a) track thickness, (b) pore diameter.

\subsection{Significance of Individual Process Parameters}

\subsubsection{Laser Power}

When the laser scans over the powder layer, the absorbed energy from the laser beam heat the Co-Cr-Mo particles creating a melt pool. Heating, time-evolution of the melt pool, and the solidification process depend on the powder and process characteristics [96]. The process parameters influence the phases, recoil pressure, surface tension, Marangoni effect, and hydrodynamics that affects the size, and shape of the melt pool. When the laser beam leaves the melt area, the melt pool starts to cool down and solidifies $[97,98]$. As such the creation of a stable melt pool with a regular shape and geometrical characteristics, the powder characteristics of Co-Cr-Mo and laser processing parameters are the significant factors. These parameters also have a direct influence on the manufacturing time and quality of the final parts.

Figure 3 shows the Co-Cr-Mo track thickness and pore diameter at varying laser power at a constant hatch spacing and scanning rate. As the laser power increases, the amount of interacting powder rises increasing the track thickness as shown in Figure 3a. At higher laser power, the Co-Cr-Mo track formation is contributed both from the particles directly and adjacent to the laser spot resulting in a denudation zone. The powder denudation zone defines the volume of powder involved in the track formation and spattering process. The process is not unique to $\mathrm{Co}-\mathrm{Cr}-\mathrm{Mo}$ and is similar to most metals when processed using LPBF [99]. 
Although there is a consistent increase in $t_{t}$ with laser power, the rate of change was found to reduce gradually post $115 \mathrm{~W}$. This is because the rise in laser energy, melt convection, and thermal diffusion increases the unusable energy which cannot be completely absorbed in the powder bed. Consequently, the track thickness and laser power can be observed to have a significant influence but without an absolute proportionality throughout the laser power range considered; which is consistent with the literature $[94,100,101]$. Overall, a variation in laser power from 85 to $135 \mathrm{~W}$ was found to increase the track thickness by $\sim 26 \%$.

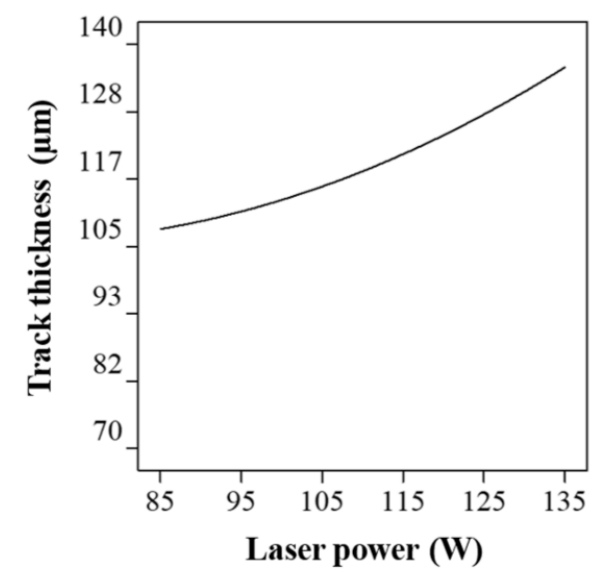

(a)

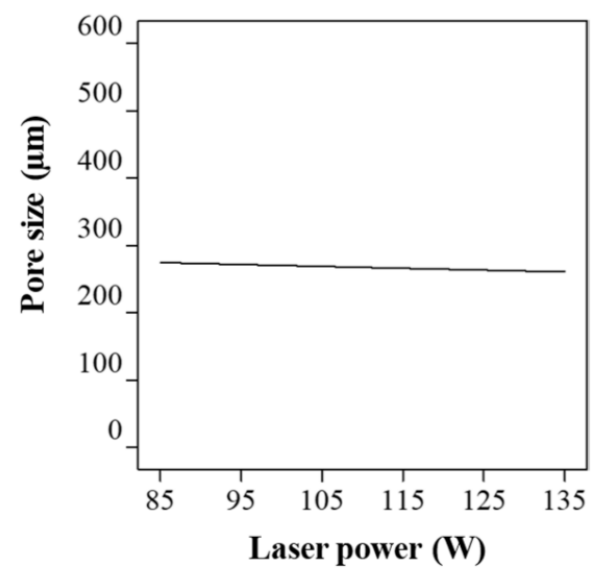

(b)

Figure 3. Influence of laser power on (a) track thickness and (b) pore size of the porous Co-Cr-Mo.

When it comes to the influence of laser power on the pore size (Figure 3b), a linear relationship was observed. It was found that the pore size was highest at $274 \mu \mathrm{m}$ when the laser power was at its lowest signifying a thinner track. As the laser power increased to $135 \mathrm{~W}$, the pore diameter reduced by $5 \%$ to $260 \mu \mathrm{m}$. As such, without considering any interaction between the process parameters, laser power has the highest influence on the track thickness, which subsequently affects the pore diameter to a lesser extent.

\subsubsection{Scanning Rate}

The scanning rate is the speed at which the laser spot travels across the powder bed. The first consideration when choosing the parameter is to achieve a consistent, fully dense track. For any given build, the powder characteristics and layer thickness are constant parameters. As such, using a fixed laser spot size leaves laser power, scanning rate, and hatch spacing as the process variables. Generally, all three of these parameters required being carefully controlled, for example, a high scanning rate can result in insufficient energy at the powder bed. This will lead to an unmelted or partially melted track featuring 'lack of fusion' porosity. In contrast, lowering the scanning rate leads to a high energy density that can overheat the melt pool, causing deeper energy penetration leading to keyhole formation and an unstable track. Therefore, there is an optimum scanning rate window that achieves a continuously fused material track. A fully dense material track is generally the aim, while the target of laser processing in this study, however, was to identify the thinnest most stable track.

The effect of scanning rate on the track thickness and the pore shape were analysed at a constant laser power and hatch spacing of $110 \mathrm{~W}$ and $0.37 \mathrm{~mm}$ respectively. The entire scanning rate range resulted in fully melted tracks. However, at a low scan rate, the laser interacts with the powder longer resulting in a thicker track. It can be seen from Figure $4 \mathrm{a}$ that the thickness of the molten Co-Cr-Mo track decreased as the scanning speed increased. However, the track thickness shows that the scanning rate has a threshold character characterised by the flattening of curves at a scanning rate around 775-875 mm/s (Figure 4a). 
Although there is a consistent increase in $t_{t}$ with laser power, the rate of change was found to reduce gradually post $115 \mathrm{~W}$. This is because the rise in laser energy, melt convection, and thermal diffusion increases the unusable energy which cannot be completely absorbed in the powder bed. Consequently, the track thickness and laser power can be observed to have a significant influence but without an absolute proportionality throughout the laser power range considered; which is consistent with the literature $[94,100,101]$. Overall, a variation in laser power from 85 to $135 \mathrm{~W}$ was found to increase the track thickness by $\sim 26 \%$.

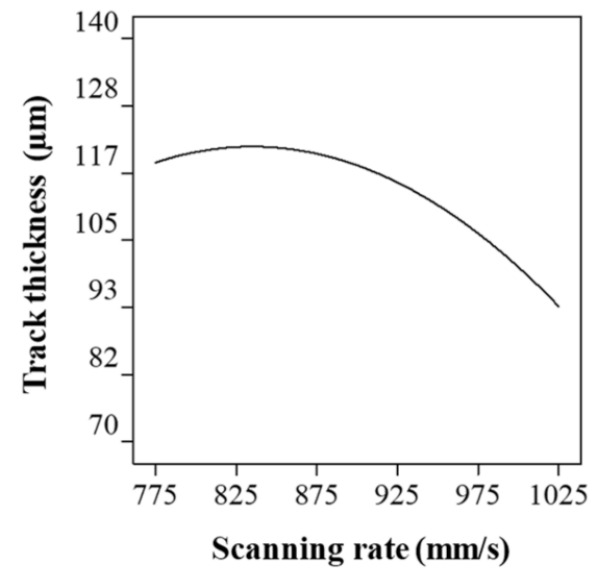

(a)

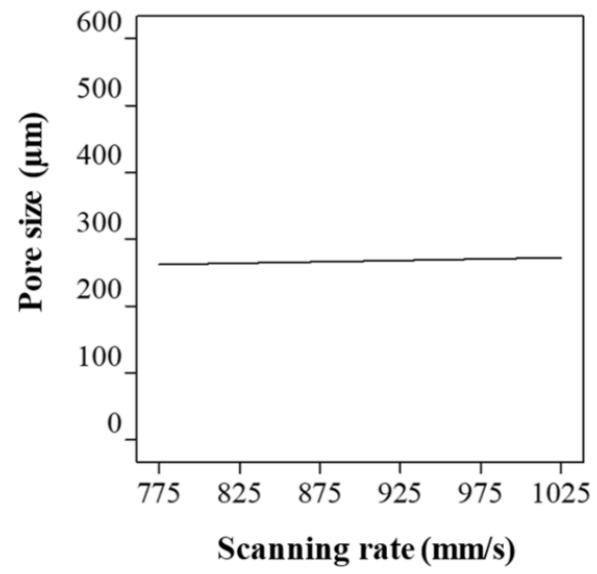

(b)

Figure 4. Influence of scanning rate on (a) track thickness and (b) pore size of LPBF Co-Cr-Mo.

Overall, the highest track thickness of $121 \mu \mathrm{m}$ was observed at a scanning rate of $825 \mathrm{~mm} / \mathrm{s}$ which reduced by $22 \%$ when the scanning rate was increased to $1025 \mathrm{~mm} / \mathrm{s}$. This is because as the scanning rate increases, the residence time of the laser per unit area reduces engaging in a lesser number of powdered particles leading to smaller melt-pool width. Nevertheless, Figure $4 \mathrm{~b}$ shows that the changing track thickness has a small influence on the pore size where the diameter of the pore increased by $\sim 4 \%$ when the scanning rate was increased from 775 to $1025 \mathrm{~mm} / \mathrm{s}$. Similar to the case of laser power, the scanning rate was found to have a significant effect on the track thickness which subsequently affected the pore size to a lesser extent. As such, both the laser power and scanning rate did not directly affect the spacing between the melted tracks leading to a lower influence on pore size.

\subsubsection{Hatch Spacing}

The next level of complexity is the melting of multiple tracks to fill the designated part area based on the design. The part area is build-up of adjacent tracks, where their overlap distance is dictated by the hatch spacing. It is measured from the centre of one laser spot to the adjacent. To have process-induced porosity such as the ones targeted in this study, a large hatch spacing is required. Otherwise, the laser tracks will overlap resulting in a fully dense part.

Figure 5 shows the influence of hatch spacing when the laser power and scanning rate are kept constant. It can be seen from Figure 5a that lower and higher hatch spacing seem to have no significant effect on the track thickness. This was expected as the hatch spacing range was deliberately chosen to not coincide or overlap with the previous track to induce a porosity. Nevertheless, a small rise in track width can be observed around a $0.37 \mathrm{~mm}$ hatch spacing which can be attributed to the effect of the powder particle size and some inconsistencies in the track formation. Only the analysis on the interaction effect will reveal the exact reason which is discussed in subsequent sections. From Figure 5b, it is evident that even at the smallest hatch spacing of $0.14 \mathrm{~mm}$ there exist a small gap between 
two consecutive laser tracks. This explains why the track thickness is unaffected despite the change in hatch spacing in Figure $5 \mathrm{a}$.

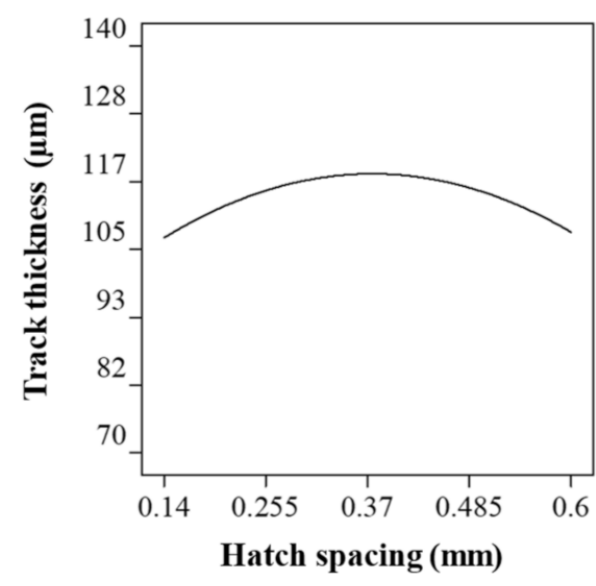

(a)

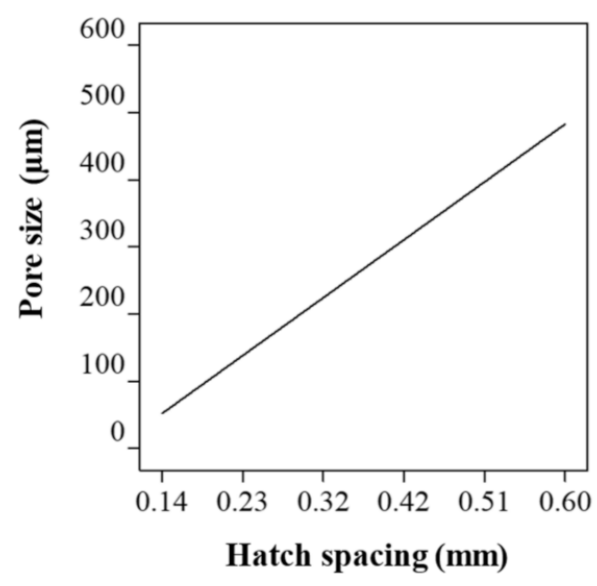

(b)

Figure 5. Influence of hatch spacing on (a) track thickness and (b) pore size of LPBF Co-Cr-Mo.

Evaluating Figure $5 b$, the hatch spacing has a significant effect on the pore size. The increase in pore diameter is linearly consistent with an increase in hatch spacing. The lowest hatch spacing was found to be $50 \mu \mathrm{m}$ at a hatch spacing of $0.14 \mathrm{~mm}$, however, this increased almost 10 folds when the hatch spacing was increased to 0.60 . Therefore, when it comes to pore size, hatch spacing has the most significant effect despite keeping all other parameters constant. The track thickness on the other hand was primarily affected by the laser power and scanning rate with almost no influence from the hatch spacing range considered. Although the study so far has identified the influence of individual process parameters on the characteristics of the $\mathrm{Co}-\mathrm{Cr}-\mathrm{Mo}$ microporous material, the interaction effects are not understood, which is discussed in subsequent sections.

\subsection{Interaction Effects between LPBF Process Parameters}

\subsubsection{Track Thickness}

Laser power, scanning rate, and hatch spacing are the three variables considered in this study. Although these parameters can be varied independently, their interaction has the most significant effect on the melt pool characteristics. Therefore, studying the interaction effects between the process parameters and identifying their order of influence is critical in identifying the optimum parametric combination. The thickness of Co-Cr-Mo track has a significant influence on the overall pore size and the surface area achievable. Ideally, a stable but thinner track offers a higher opportunity for functional porosity as opposed to thicker tracks. As such identifying and accurately characterising the interaction effects between the LPBF process parameters is carried out to inform the optimised microporous material.

The interaction effects between the process parameters affecting the Co-Cr-Mo track thickness are shown in Figure 6. As can be seen, the parameters behaved differently depending on their combination with other parameters being used. By observing the influence of scanning rate and hatch spacing as shown in Figure 6a, it can be seen that track thickness was slightly decreased as the scanning rate increased, resulting in the thinnest track at the highest scan speed with minimal influence from hatch spacing. As such, the interaction effects between scanning rate and hatch spacing on Co-Cr-Mo track thickness were insignificant, which is consistent with the single-parameter observations. This was expected as the hatch spacing range was deliberately chosen for porosity rather than to allow melt-pool overlap. A similar trend was observed regarding the interaction effects between laser power and hatch spacing, as shown in Figure 6b. Here, the thickness of the track was primarily driven by the laser energy with negligible interaction with hatch spacing. As such, $t_{t}$ increased consistently with the intensity of the laser power. 
Overall, both Figure $6 \mathrm{a}, \mathrm{b}$ show that hatch spacing has minimal influence when it comes to track thickness.

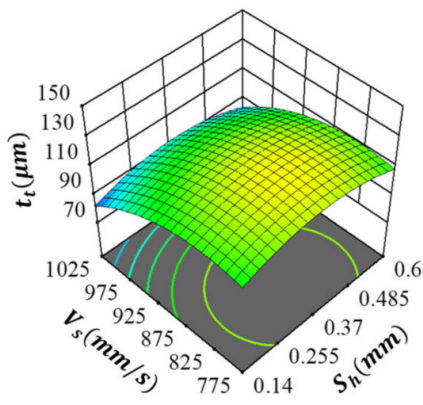

(a)

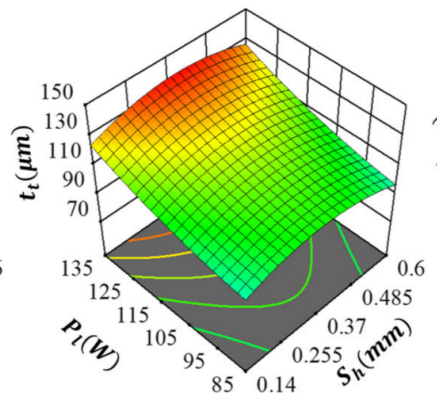

(b)

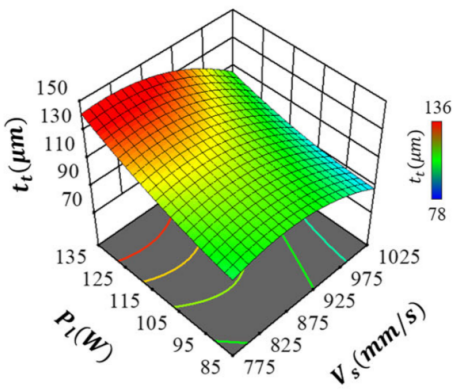

(c)

Figure 6. Influence of LPBF process parameters on Co-Cr-Mo track thickness showing interaction effects between (a) hatch spacing and scanning rate, (b) hatch spacing and laser power and (c) scanning rate and laser power.

As shown in Figure 6c, the Co-Cr-Mo track thickness is primarily dictated by $P_{l}$ and $V_{s}$ with significant interaction effects between the two parameters. Therefore, achieving the thinnest track required careful control of both scanning rate and laser power. The strong interaction effects mean that the thinnest track was formed when both the laser power and scanning rate were at their lowest. As such, controlling either $P_{l}$ or $V_{s}$ without considering their interaction is unlikely to achieve the thinnest possible LPBF process-induced CoCr-Mo track. Deriving the order of influence, the most significant terms on $t_{t}$ are the interaction effects of $V_{s}$ and $P_{l}$ in the order $P_{l} V_{s}>V_{s}>P_{l}$ with the least influence from $S_{h}$. Consequently, to generate the finest porous $\mathrm{Co}-\mathrm{Cr}-\mathrm{Mo}$ architecture, a higher scan speed and lower laser power that induces sufficient energy density for the thinnest but fully melted track thickness is required.

\subsubsection{Pore Diameter}

The pore diameter is primarily dictated by the hatch spacing, as evident from Figure 7a, with no influence from scanning rate or laser power, as shown in Figure $7 \mathrm{~b}, \mathrm{c}$, respectively. The dependency of pore diameter on the hatch distance is also linear with the smallest and largest $\phi_{d}$, consistent with hatch spacing, as shown in Figure 7a,b. This response was expected as the parameter driving the distance between two adjacent tracks is hatch spacing. As shown in Figure $7 \mathrm{a}, \mathrm{b}$, variations in $V_{s}$ or $P_{l}$ cannot introduce any changes to pore diameter, as signified by identical response surfaces. It can be also seen that there are no interaction effects between $V_{s}$ and $P_{l}$, as well demonstrated by the flat cure in Figure $7 \mathrm{c}$. As such, the most significant term dictating the pore diameter of $\mathrm{Co}-\mathrm{Cr}-\mathrm{Mo}$ is the first-order effects of hatch spacing.

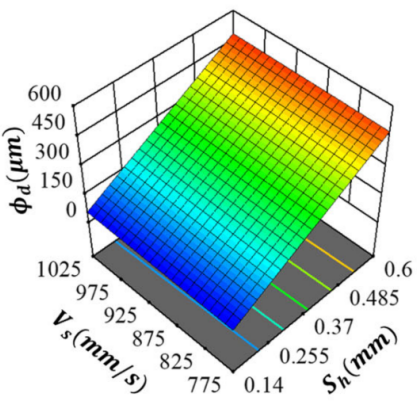

(a)

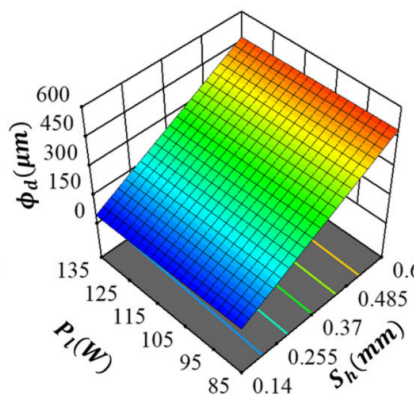

(b)

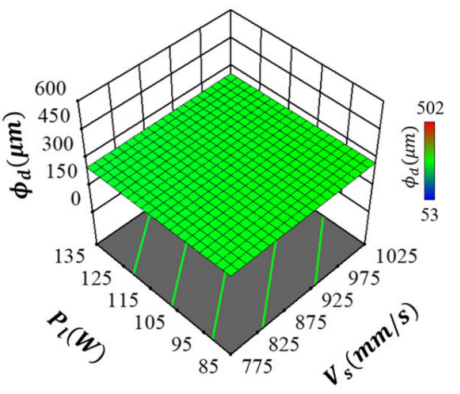

(c)

Figure 7. Influence of process parameters on the pore diameter of $\mathrm{Co}-\mathrm{Cr}$-Mo showing the interaction effects between (a) hatch spacing and scanning rate, (b) hatch spacing and laser power and (c) scanning rate and laser power. 
The influence of process parameters on both track thickness and pore diameter reveals that the interaction effects can be used to simplify the Co-Cr-Mo microporous printing process. Overall, the targeted porosity can be achieved by carefully modulating the process parameters, which allows ease of customisability, and scalability. The influence of the process parameters on the material has also been analytically represented, which allows identifying the most optimal parametric combination based on the requirement. For the study under consideration a fine $\left(<t_{t}\right.$ and $\left.<\phi_{d}\right)$ architecture suitable for antiviral evaluation is the aim. The analysis so far shows that this can be achieved by minimising $P_{l}$ and $S_{h}$ while maximising $V_{s}$ which results in thinner tracks as close as possible but not so close as to introduce a dense part.

\subsection{Multi-Objective Optimisation}

\subsubsection{Predicting Optimal Solution}

The analysis so far has demonstrated the influence of the process parameters in the development of $\mathrm{Co}-\mathrm{Cr}-\mathrm{Mo}$ porous material. However, an accurate parametric combination that will lead to the best possible porous architecture is yet to be established. Doing this requires a multi-objective numerical description of the optimisation problem. To maximise the antiviral load, the optimum Co-Cr-Mo material should be porous in a way that maximises the surface area while featuring stable and consistent tracks. In other words, the optimised structure should allow for the smallest $\phi_{d}$ without producing a dense structure while featuring the thinnest $t_{t}$. This means that the multi-objectives algorithm should look for a desirability criterion to minimise both $\phi_{d}$ and $t_{t}$ to a non-zero positive integer. In this regard, the optimisation problem can be formulated as shown in Equation (3):

$$
\left\{\begin{aligned}
\text { Minimise } t_{t} & =f_{1}\left(S_{h}, V_{s}, P_{l}\right) \\
\text { Minimise } \phi_{d} & =f_{2}\left(S_{h}, V_{s}, P_{l}\right) \\
\text { s.t } \quad 0.14 & \leq S_{h} \leq 0.6 \\
\text { s.t } \quad 775 & \leq V_{s} \leq 1025 \\
\text { s.t } \quad 85 & \leq P_{l} \leq 135
\end{aligned}\right.
$$

A multi-objective optimisation problem usually yields multiple solutions. As such a desirability function is used to combine them into a single objective (D) that meets the desirable range for each response $\left(d_{i}\right)$. The desirability approach is one of the most widely used methods in parametric optimisation where multiple responses are involved. It is based on the idea that the targeted outcome has multiple desired characteristics, any solution where the outcomes fall outside the desired limits is inadequate. Using this technique, the least and most desirable outcomes can be represented between 0 and 1 respectively. When $n$ is the number of responses, the multi-objective function is a geometric mean of all transformed responses as shown in Equation (4):

$$
D=\left(d_{1} \cdot d_{2} \cdot \ldots \cdot d_{n}\right)^{\frac{1}{n}}=\left(\prod_{i=1}^{n} d_{i}\right)^{\frac{1}{n}}
$$

Figure 8 shows the results of the multi-objective optimisation as a desirability function considering all interaction effects informed by the surrogate model. The highest desirability of 0.9 can be achieved at a scanning rate of $975-1025 \mathrm{~mm} / \mathrm{s}$, laser power of $85-105 \mathrm{~W}$, and a hatch spacing of $0.14 \mathrm{~mm}$. Before identifying the exact numerical values, it was important to consider particle size, which in this case ranged from 3 to $18 \mu \mathrm{m}$. This was set to prevent the powder particles from getting stuck in the pores leading to a dense part. As can be seen from Figure 8a, despite keeping the other parameters constant increasing the laser power decreases the desirability. Overall, the lowest desirable solution is at the lowest scan speed, hatch distance, and highest laser power as shown in Figure 8c. Table 4 shows one of the parametric combinations that offer the highest desirability that was used to fabricate the Co-Cr-Mo validation sample. 


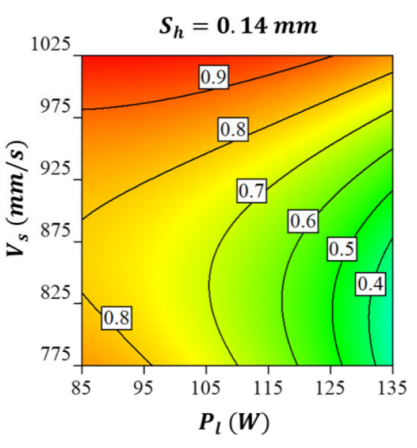

(a)

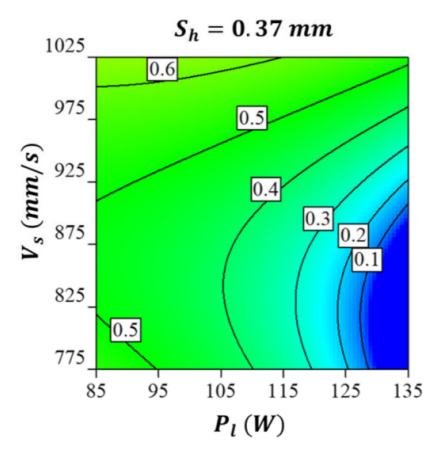

(b)

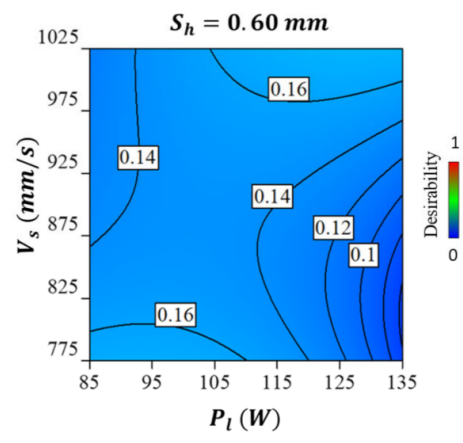

(c)

Figure 8. The desirability of the optimum solution for the Co-Cr-Mo microporous LPBF material showing (a) the effect of scanning rate and laser power at a hatch spacing of $0.14 \mathrm{~mm}(\mathbf{b})$ the effect of scanning rate and laser power at a hatch spacing of $0.37 \mathrm{~mm}$ and (c) effect of scanning rate and laser power at a hatch spacing of $0.60 \mathrm{~mm}$. A desirability contour of 0 and 1 refer to the least and most optimum solution, respectively.

Table 4. Optimal LPBF parametric combination selected for Co-Cr-Mo validation build.

\begin{tabular}{ccccc}
\hline Number & $S_{h}(\mathbf{m m})$ & $V_{s}(\mathbf{m m} / \mathbf{s})$ & $\boldsymbol{P}_{l}(\mathbf{W})$ & Desirability \\
\hline 1 & 0.14 & 1025 & 88 & 0.98 \\
\hline
\end{tabular}

\subsubsection{Fabrication and Validation of the Optimised Co-Cr-Mo Architecture}

Co-Cr-Mo samples were additively manufactured using the predicted LPBF process parameter combinations listed in Table 4 . The printed sample was analysed under SEM which confirms a fine porous architecture as shown in Figure 9a. The magnified Figure 9b confirms an even and consistent track and pore formation. Any further reduction in pore diameter runs the risk of powder particles becoming embedded in the porosity. As such the predicted optimum architecture by the surrogate model is closer to the potential porosity limit that can be achieved using the current particle and laser spot size.

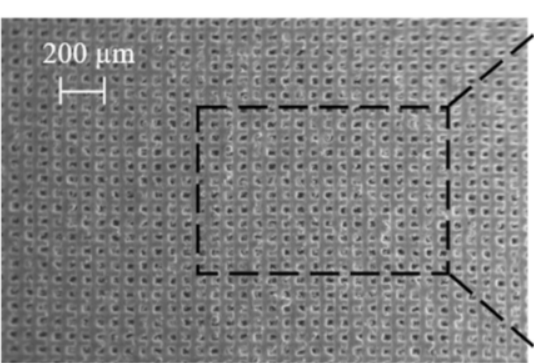

(a)

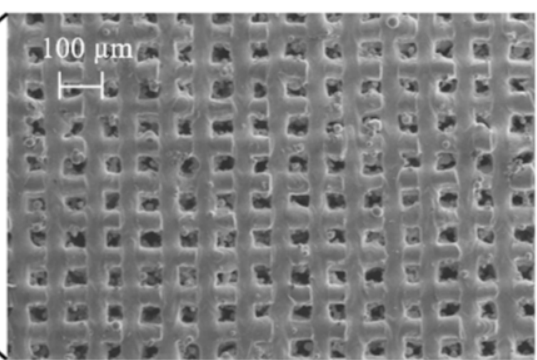

(b)

Figure 9. SEM data of as-built LPBF processed optimum Co-Cr-Mo microporous architecture showing (a) the overall pore distribution at a scale of $200 \mu \mathrm{m}(\mathbf{b})$ a highlighted section showing the quality of the tracks and pores.

The results from the experimentally measured optimum $\mathrm{Cu}-\mathrm{W}-\mathrm{Ag}$ microporous material when compared to the surrogate model can be seen to be in good agreement as listed in Table 5. Overall, the surrogate model overestimated the track thickness and pore diameter by 3.9 and $3.2 \%$ respectively. This small change between the predicted and experimented data can be attributed to the influence of particle size and partially melted powder at the track boundaries. Overall, the results show that the Co-Cr-Mo porous architecture with a feature size of $75 \mu \mathrm{m}$ and pore diameter of $61 \mu \mathrm{m}$ is achievable using LPBF, which transcends the current state-of-the-art feature size of $300 \mu \mathrm{m}$. As such, any further refinement in achievable pore size requires finer feedstock and further adjustments in laser modulation. 
Subsequently, the as-built Co-Cr-Mo optimised porous material was used for antiviral testing against the SARS-CoV-2 viral model to evaluate its antiviral effectiveness.

Table 5. Comparison between actual and predicted values of the optimum Co-Cr-Mo microporous material on track thickness $\left(t_{t}\right)$ and pore diameter $\left(\phi_{d}\right)$.

\begin{tabular}{ccc}
\hline Item & $\boldsymbol{t}_{\boldsymbol{t}}(\boldsymbol{\mu \mathrm { m }})$ & $\boldsymbol{\phi}_{\boldsymbol{d}}(\boldsymbol{\mu \mathrm { m }})$ \\
\hline Predicted & 78 & 63 \\
Actual & 75 & 61 \\
Difference $(\%)$ & $3.9 \%$ & $3.2 \%$ \\
\hline
\end{tabular}

\subsection{Antiviral Characterisation}

The optimised microporous Co-Cr-Mo material was printed, and antiviral tests were performed $(n=3)$ against the biosafe vrial model of SARS-CoV-2. The antiviral performance is summarised in Table 6, where the data at $30 \mathrm{~min}$ and $5 \mathrm{~h}$ compared against a control sample, commercial porous fabric, and current state-of-the-art copper architecture. The corresponding visuals of the samples at $30 \mathrm{~min}$ and $5 \mathrm{~h}$ of contact with the phage are presented in Figure 10. The control sample did not exhibit any antiviral activity at $30 \mathrm{~min}$ or $5 \mathrm{~h}$ as shown in Figure 10a,d, respectively. The commercial porous fabric, which was used as a reference material showed no antiviral performance at $30 \mathrm{~min}$ (Figure 10b) or $5 \mathrm{~h}$ (Figure 10e) as expected. In comparison, the optimised Co-Cr-Mo LPBF porous architecture resulted in 100\% viral inactivation at both contact times where no plaques can be observed as shown in Figure 10c,f, respectively.

Table 6. Antiviral performance of the control samples (control and porous fabric) and the developed Co-Cr-Mo porous material using a viral model of SARS-CoV-2 and the antiviral activity of $\mathrm{Cu}$ from the literature.

\begin{tabular}{|c|c|c|c|c|c|}
\hline \multirow{3}{*}{ Identifier } & \multirow{3}{*}{ Material } & \multicolumn{4}{|c|}{ Antiviral Activity } \\
\hline & & \multicolumn{2}{|c|}{$30 \mathrm{~min}$} & \multicolumn{2}{|c|}{$5 \mathrm{~h}$} \\
\hline & & $\log$ & $\%$ & $\log$ & $\%$ \\
\hline$\# 1$ & Control & 0 & $0 \%$ & 0 & $0 \%$ \\
\hline \#2 & Porous fabric & 0 & $0.1 \%$ & 0 & $2.8 \%$ \\
\hline$\# 3$ & Co-Cr-Mo & -6 & $100 \%$ & -6 & $100 \%$ \\
\hline Hutasoit et al. [82] & $\mathrm{Cu}$ & -0.4 & $\approx 0 \%$ & -2.2 & $99.2 \%$ \\
\hline
\end{tabular}

The results revealed that the novel Co-Cr-Mo microporous architecture developed in this study have excellent antiviral properties (100\% viral inactivation in $30 \mathrm{~min})$ against phage phi 6 used as enveloped RNA viral model of SARS-CoV-2. The antiviral performance of the Co-Cr-Mo porous material is also superior to the current state-of-the-art copper [82], which showed $99.2 \%$ inactivation of SARS-CoV-2 in $5 \mathrm{~h}$ and no antiviral performance at $30 \mathrm{~min}$ as compared in Table 6. Generally, the SARS-CoV-2 virus can survive for $4-5$ days in a range of materials [105] such as plastics, ceramics, stainless steel and glass as listed in Table 1. As such this paper presents the first metallic material that shows high ( $<30 \mathrm{~min}$ ) antiviral performance against an enveloped virus like SARS-CoV-2 and influenza virus. This means that the material is suitable to be used as permanent antiviral devices aiding response against viral pathogens. Further development in this direction can aid pandemic preparedness to protect human beings in a more effective way while reducing the environmental impacts of disposable viral control devices in critical environments. 


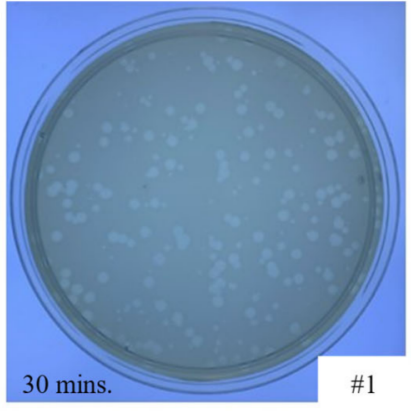

(a)

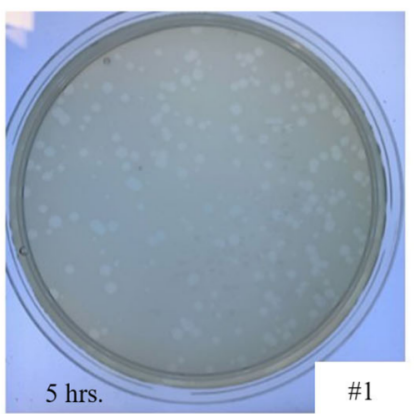

(d)

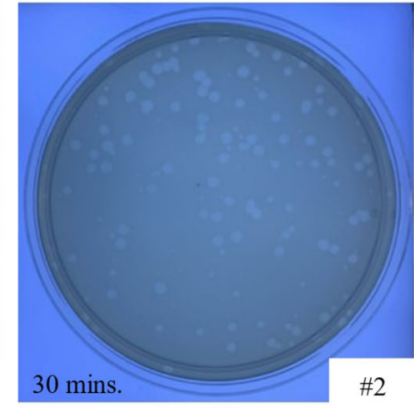

(b)

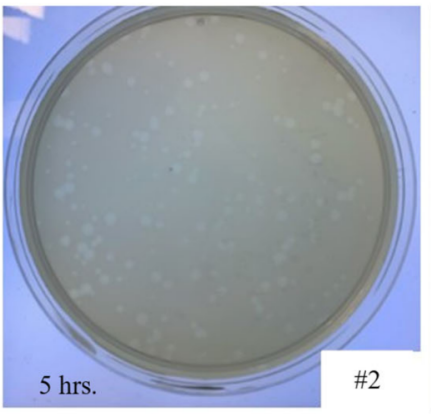

(e)

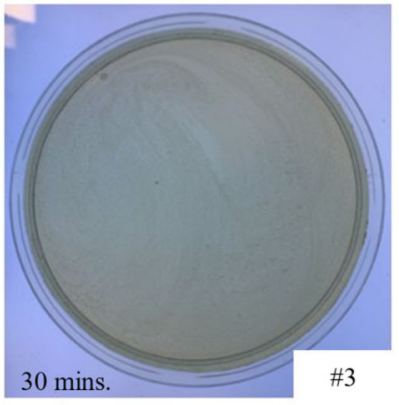

(c)

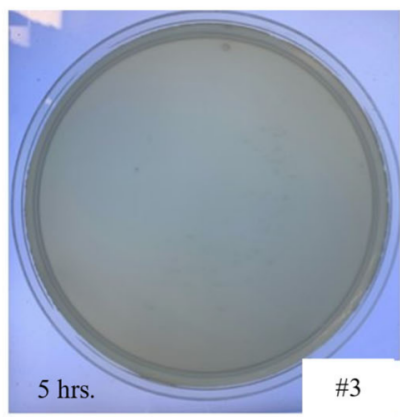

(f)

Figure 10. Loss of phage phi6 viability measured by the double-layer method at $10^{-1}$ dilution, showing the phage in contact with (a) control sample after $30 \mathrm{~min}$, (b) commercial porous fabric after $30 \mathrm{~min}$, (c) Co-Cr-Mo porous material after $30 \mathrm{~min}$, (d) control sample after $5 \mathrm{~h}$, (e) commercial porous fabric after $5 \mathrm{~h}$, and (f) Co-Cr-Mo porous material after $5 \mathrm{~h}$.

\section{Materials and Methods}

\subsection{Laser Powder Bed Fusion (LPBF)}

The EOS M290 LPBF machine was used to fabricate the samples at a constant layer thickness of $30 \mu \mathrm{m}$. The system featured a $400 \mathrm{~W} \mathrm{Yb-fibre} \mathrm{laser} \mathrm{that} \mathrm{is} \mathrm{modulated} \mathrm{above}$ the powder bed within a $250 \times 250 \mathrm{~mm}$ build platform. Table 7 shows the composition ( $w t . \%$ ) of the atomised Co-Cr-Mo alloy used as feedstock at the powder bed. The LPBF process parameters namely the laser power $\left(P_{l}\right)$, hatch spacing $\left(S_{h}\right)$ and scanning rate $\left(V_{s}\right)$ was informed by the surrogate model which is discussed in subsequent sections. The bulk density of the material is $8.3 \mathrm{~g} / \mathrm{cm}^{3}$ with the morphology of the particles as shown in Figure 1. The particles featured a spherical morphology with occasional irregular shapes representative of typical feedstock suitable for LPBF. Some smaller satellite particles around $3 \mu \mathrm{m}$ can be seen attached to larger particles around $18 \mu \mathrm{m}$. The overall sphericity and particle size range was found to be favourable for the powder bed fusion process and resulted in even powder spread.

Table 7. Composition of the Co-Cr-Mo alloy used as feedstock for LPBF processing.

\begin{tabular}{ccccccccc}
\hline Elements & Co & Cr & Mo & Si & Mn & Fe & C & Ni \\
\hline Composition (wt. \%) & $60-65$ & $26-30$ & $5-7$ & $\leq 1.0$ & $\leq 1.0$ & $\leq 0.75$ & $\leq 0.16$ & $\leq 0.1$ \\
\hline
\end{tabular}

The laser processing was carried out in an argon inert atmosphere at $<0.1 \%$ oxygen on a steel substrate of temperature $35^{\circ} \mathrm{C}$. The number of samples was informed by the required parametric combinations randomised by the surrogate model. The LPBF process prints follow a layer-by-layer method where the build platform is lowered by the constant layer thickness between subsequent layers. Post-printing the samples were heat-treated at $1050^{\circ} \mathrm{C}$ for six hours in an argon atmosphere. The resulting track thickness and pore dimensions were characterised using scanning electron microscopy (SEM). EVO 50 SEM 
produced by Zeiss that uses an incident electron beam to interact with the printed sample to generate backscattered and secondary electrons to create an image of the porous sample is used (Figure 11) [48-52].

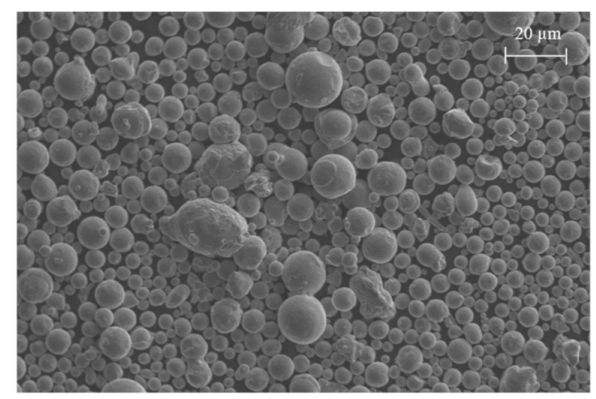

Figure 11. Scanning electron micrograph of Co-Cr-Mo feedstock showing particle morphology.

\subsection{Surrogate Modelling}

In $\mathrm{LPBF}$, the extent of material melting and track formation is dictated by the energy density $\left(e_{l d}\right)[106]$ at the powder bed which is given by Equation (5):

$$
e_{l d}=\frac{P_{l}}{V_{s} \times S_{h} \times t_{l}}
$$

where $P_{l}$ is the laser power $(\mathrm{W}), V_{s}$ is the scanning rate $(\mathrm{mm} / \mathrm{s}), S_{h}$ is the hatch spacing $(\mathrm{mm})$, and $t_{l}$ is the layer thickness. The relationship between the LPBF process parameters and the energy density at the powder bed means that the parameters can be controlled for the targeted outcome. Traditionally, this approach is used to identify the optimal energy density required to fully melt and fuse the feedstock, resulting in a stable track. Building on this relationship, this study attempted to identify the required LPBF parametric combinations to create a Co-Cr-Mo construct with controllable pore size and track thickness. To carry this out, the relationship between the LPBF process parameters is linked to an objective function of the resulting architecture using Equation (6):

$$
\left\{\begin{array}{c}
f(x)=\left[f_{1}(x), f_{2}(x), \ldots \ldots, f_{i}(x)\right] \\
\text { s.t } \quad x^{l} \leq x \leq x^{u}
\end{array}\right.
$$

where $x=\left(x_{1}, x_{2}, \ldots, x_{k}\right)$ is the vector of the $k$ LPBF process variables for Co-Cr-Mo. The maximum and minimum limits associated with each process parameter are defined by $x^{l}$ and $x^{u}$ for the objective function $f(x)$. Printing porous $\mathrm{Co}-\mathrm{Cr}$-Mo requires characterising the order of influence of the LPBF variables that leads to specific responses. The methodology was to vary the laser energy at the powder bed by algorithmically modifying the LPBF parameters $P_{l}, S_{h}$, and $V_{s}$ to inform the track thickness $\left(t_{t}\right)$ and pore diameter $\left(\phi_{d}\right)$, as shown in Figure 12.

The parametric combination of the randomised training matrix for the surrogate model was conceived based on the Box-Behnken design (BBD) principle. BBD was chosen as it allows for higher-order response surfaces using fewer required runs than a normal factorial technique in the training matrix. As such it is an alternative to the $3^{k}$ factorial that results in an efficient sampling matrix of the coded factorial levels. This approach generally results in a good fit with sufficient information to test for lack of fit. The method also allows models of increasing order to be constructed sequentially and allows for an estimation of experimental error. 


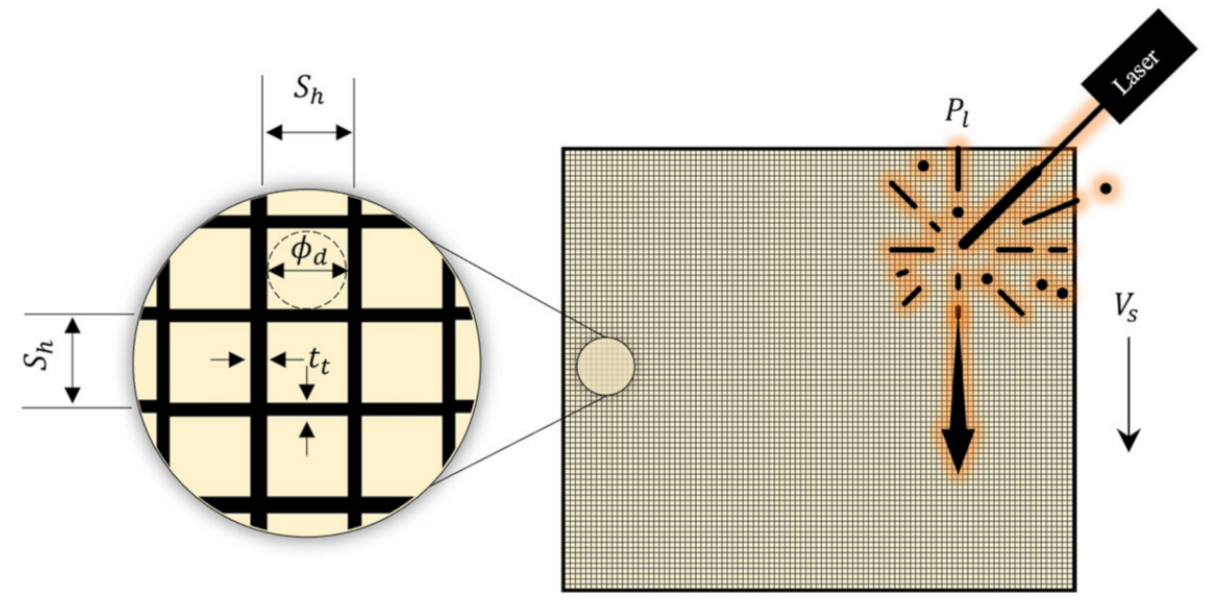

Figure 12. Problem description used for surrogate modelling showing the LPBF variables $\left(P_{l}, S_{h}\right.$ and $\left.V_{s}\right)$ and measured responses $\left(t_{t}\right.$ and $\left.\phi_{d}\right)$ for the Co-Cr-Mo anti-SARS-CoV-2 porous architecture. Note: $S_{h}$ is the hatch spacing, $V_{s}$ is the scanning rate, $P_{l}$ is the laser power, $t_{t}$ is the track thickness and $\phi_{d}$ is the pore diameter.

The limits of the LPBF process parameters considered for the coded BBD factorial matrix are summarised in Table 8 . Based on the problem description, regression analysis was used to characterise the relationship between the LPBF process variables and the resulting responses of the Co-Cr-Mo printed samples. Subsequently, best fit empirical models were derived through randomised experimental data measured for the responses $t_{t}$ and $\phi_{d}$. The resulting polynomial functions were used to predict the order of influence of the contributing process parameters on the responses of the Co-Cr-Mo printed samples.

Table 8. LPBF process variable ranges considered for the Co-Cr-Mo surrogate model.

\begin{tabular}{ccccccc}
\hline Variables & Description & Units & Codes & Min. & Med. & Max. \\
\hline$S_{h}$ & Hatch spacing & $\mathrm{mm}$ & $\mathrm{A}$ & 0.14 & 0.37 & 0.60 \\
$V_{s}$ & Scanning rate & $\mathrm{mm} / \mathrm{s}$ & $\mathrm{B}$ & 775 & 900 & 1025 \\
$P_{l}$ & Laser power & $\mathrm{W}$ & $\mathrm{C}$ & 85 & 110 & 135 \\
\hline
\end{tabular}

The steps that led to the development of an accurate surrogate model is summarised in Figure 13. The surrogate model was trained using randomised test data to satisfy the sampling matrix and analysis of variance criteria. The predictions of the trained model were evaluated for accuracy followed using a desirability criterion to identify the optimum parametric combination that leads to the thinnest Co-Cr-Mo melt tracks and smallest pore diameter. This optimum criterion was chosen to minimise pore diameter and track thickness to accommodate the highest number of pores as possible. The surrogate model was subsequently used to quantify the interaction effects of the process parameters and their influence on the Co-Cr-Mo porous architecture.

\subsection{Antiviral Characterisation}

The phage phi6 host culture was carried using Pseudomonas syringae from the DSMZGerman collection of microorganisms and cell cultures (DSM 21482) in solid Tryptic Soy Agar (TSA, Liofilchem). Post culture, the bacteria were incubated in liquid Tryptic Soy Broth (TSB, Liofilchem) at $120 \mathrm{rpm}$ and at $25^{\circ} \mathrm{C}$. Pseudomonas phage phi6 titration was carried out in accordance with specifications for phage infection.

Phi6 is a double-stranded RNA virus with three-part, segmented, totalling $\sim 13.5 \mathrm{~kb}$ in length. This type of lytic bacteriophage belongs to Group III Baltimore classification and was chosen as SARS-CoV-2 viral model (Group IV: positive-sense single-stranded RNA viruses) as it features a lipid membrane around their nucleocapsid. According to Kitajima et al. [107] low pathogenic CoV strains (such as MHV and classical human CoVs) 
or the same enveloped Pseudomonas phage phi6 can be used as models of SARS-CoV-2 considering biosafety [108]. Furthermore, recent experiments performed with Phi6 and SARS-CoV-2 have validated the use of this biosafe viral model [26].

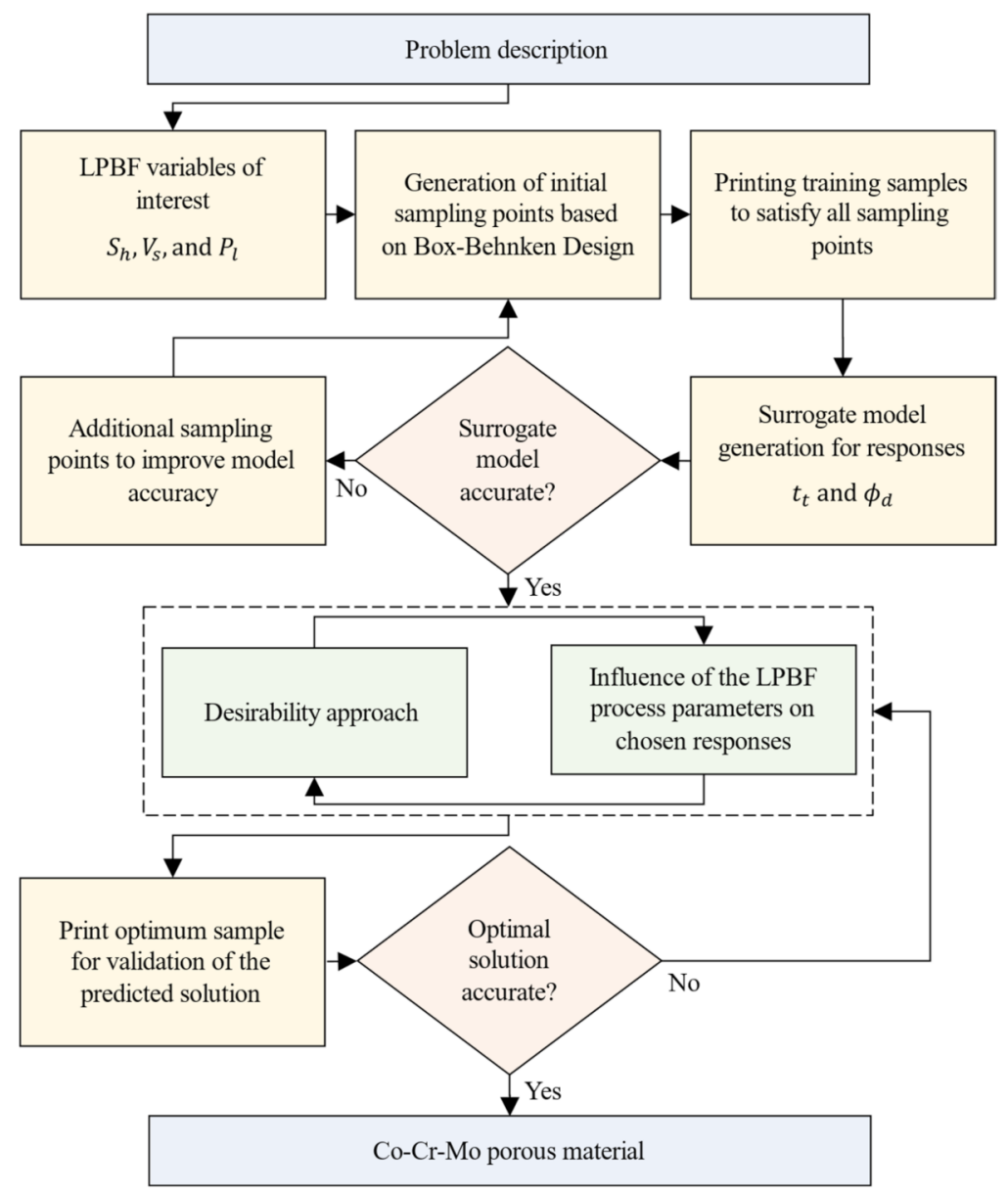

Figure 13. The surrogate modelling methodology for LPBF Co-Cr-Mo porous material. Note: $S_{h}$ is the hatch spacing, $V_{s}$ is the scanning rate, $P_{l}$ is the laser power, $t_{t}$ is the track thickness and $\phi_{d}$ is the pore diameter.

LPBF processed Co-Cr-Mo porous samples $(n=3)$ of $10 \mathrm{~mm}$ dia. were characterised. A non-woven spunlace fabric filter from NV EVOLUTIA (commercial filters used for face masks) of $10 \mathrm{~mm}$ in diameter was cut with a cylindrical punch and used as reference material. All samples were dried at $60{ }^{\circ} \mathrm{C}$ for $24 \mathrm{~h}$ between glass plates and sterilised in ethanol/distilled water (70:30 vol.\%) solution for $5 \mathrm{~min}$ at $25^{\circ} \mathrm{C}$ and UV radiated for an hour on each side.

The antiviral activity of the samples was measured at $30 \mathrm{~min}$ and five hours of contact with the biosafe viral model. A $50 \mu \mathrm{L}$ volume of phage suspension in TSB was introduced into each sample at a concentration of $1 \times 10^{6}$ plaque-forming units per $\mathrm{mL}(\mathrm{PFU} / \mathrm{mL})$ and incubated for $30 \mathrm{~min}$ and $5 \mathrm{~h}$, respectively. Then the samples were placed in a falcon tube with $10 \mathrm{~mL}$ TSB and sonicated for $5 \mathrm{~min}$ at $24{ }^{\circ} \mathrm{C}$ and vortexed for $1 \mathrm{~min}$. Serial dilutions of each falcon were made and $100 \mu \mathrm{L}$ of each phage dilution were placed in contact with $100 \mu \mathrm{L}$ of the host strain at $\mathrm{OD}_{600 \mathrm{~mm}}=0.5$. The infective capacity of the phage was measured by the double-layer method where $4 \mathrm{~mL}$ of top agar (TSB $+0.75 \%$ bacteriological agar, Scharlau) and $5 \mathrm{mM} \mathrm{CaCl}_{2}$ were introduced to the phage-bacteria mix. The mixture was poured on TSA plates that were incubated for $24-48 \mathrm{~h}$ in an oven at $25^{\circ} \mathrm{C}$. 


\section{Conclusions}

This study demonstrates the use of Laser Powder Bed Fusion for on-demand manufacturing of a novel Co-Cr-Mo porous material that shows superior antiviral activity outperforming common antiviral metals such as silver and copper. The paper reveals a surrogate model that allows porosity personalisation without the need for complex geometry data. This is achieved through controlling the LPBF process parameters such as laser power, scanning rate and hatch spacing. The proposed methodology simplifies the data requirement and pre-processing often required for printing porous materials. The surrogate model developed in this study showed that the most significant parameters for Co-Cr-Mo track thickness $\left(t_{t}\right)$ were the interaction effects of scanning rate $\left(V_{s}\right)$ and laser power $\left(P_{l}\right)$ in the order $P_{l} V_{s}>V_{s}>P_{l}$. For pore diameter $\left(\phi_{d}\right)$, the hatch spacing $\left(S_{h}\right)$ has the most significant effect. The optimised Co-Cr-Mo microporous materials showed $100 \%$ viral inactivation against the phage phi 6 used as enveloped RNA viral model of SARS-CoV-2 in $30 \mathrm{~min}$. The evolution of this and future pandemics will bring unexpected situations where the ability to print and personalise on-demand antiviral materials can achieve rapid solutions. Furthermore, the proposed methodology can be adopted to conceive functional antiviral materials that can be fabricated close to point-of-care.

Author Contributions: Conceptualization, formal analysis, funding acquisition, project administration, resources, software, validation, visualization, writing-review and editing: Á.S.-A., A.A., J.R., A.B.; data curation: A.T.-M., Á.S.-A., A.A., J.R., A.B.; investigation: A.T.-M., M.M., Á.S.-A., A.A., J.R., A.B.; methodology: M.M., Á.S.-A., A.A., J.R., A.B.; supervision: M.M., Á.S.-A., A.A., J.R., A.B.; writing-original draft preparation: A.A. All authors have read and agreed to the published version of the manuscript.

Funding: This research was conducted with support from the CALMERIC grant (European Commission, Grant number: 32R19P03053); University of Wolverhampton; Additive Analytics UK and EOS GmbH. This research was also founded by the Fundación Universidad Católica de Valencia San Vicente Mártir, Grant 2020-231-006UCV and the Spanish Ministry of Science and Innovation (PID2020-119333RB-I00/AEI/10.13039/501100011033).

Institutional Review Board Statement: Not applicable.

Informed Consent Statement: Not applicable.

Data Availability Statement: Data is contained within the article.

Acknowledgments: The authors would like to express their gratitude to the European Commission, University of Wolverhampton, Additive Analytics UK, EOS GmbH, Fundación Universidad Católica de Valencia San Vicente Mártir, and the Spanish Ministry of Science and Innovation.

Conflicts of Interest: The authors declare no conflict of interest.

\section{References}

1. Corman, V.M.; Muth, D.; Niemeyer, D.; Drosten, C. Hosts and Sources of Endemic Human Coronaviruses. Adv. Virus Res. 2018, 100, 163-188. [PubMed]

2. Yang, X.; Yu, Y.; Xu, J.; Shu, H.; Xia, J.; Liu, H.; Wu, Y.; Zhang, L.; Yu, Z.; Fang, M.; et al. Clinical course and outcomes of critically ill patients with SARS-CoV-2 pneumonia in Wuhan, China: A single-centered, retrospective, observational study. Lancet Respir. Med. 2020, 8, 475-481. [CrossRef]

3. Hassan, S.S.; Attrish, D.; Ghosh, S.; Choudhury, P.P.; Uversky, V.N.; Aljabali, A.A.A.; Lundstrom, K.; Uhal, B.D.; Rezaei, N.; Seyran, M.; et al. Notable sequence homology of the ORF10 protein introspects the architecture of SARS-CoV-2. Int. J. Biol. Macromol. 2021, 181, 801-809. [CrossRef] [PubMed]

4. Hassan, S.S.; Aljabali, A.A.A.; Panda, P.K.; Ghosh, S.; Attrish, D.; Choudhury, P.P.; Seyran, M.; Pizzol, D.; Adadi, P.; Abd El-Aziz, T.M.; et al. A unique view of SARS-COV-2 through the lens of ORF8 protein. Comput. Biol. Med. 2021, 133, 104380. [CrossRef] [PubMed]

5. Vellingiri, B.; Jayaramayya, K.; Iyer, M.; Narayanasamy, A.; Govindasamy, V.; Giridharan, B.; Ganesan, S.; Venugopal, A.; Venkatesan, D.; Ganesan, H.; et al. COVID-19: A promising cure for the global panic. Sci. Total Environ. 2020, 725, 138277. [CrossRef]

6. American Lung Association. Learn About Pneumonia; American Lung Association: Chicago, IL, USA, 2020.

7. Singhal, T. A Review of Coronavirus Disease-2019 (COVID-19). Indian J. Pediatr. 2020, 87, 281-286. [CrossRef] [PubMed]

8. Bai, Y.; Yao, L.; Wei, T.; Tian, F.; Jin, D.Y.; Chen, L.; Wang, M. Presumed Asymptomatic Carrier Transmission of COVID-19. JAMA J. Am. Med. Assoc. 2020, 323, 1406-1407. [CrossRef] [PubMed] 
9. Wang, L.; Didelot, X.; Yang, J.; Wong, G.; Shi, Y.; Liu, W.; Gao, G.F.; Bi, Y. Inference of person-to-person transmission of COVID-19 reveals hidden super-spreading events during the early outbreak phase. Nat. Commun. 2020, 11, 1-6. [CrossRef] [PubMed]

10. Liu, Y.; Ning, Z.; Chen, Y.; Guo, M.; Liu, Y.; Gali, N.K.; Sun, L.; Duan, Y.; Cai, J.; Westerdahl, D.; et al. Aerodynamic analysis of SARS-CoV-2 in two Wuhan hospitals. Nature 2020, 582, 557-560. [CrossRef]

11. Richard, M.; Kok, A.; de Meulder, D.; Bestebroer, T.M.; Lamers, M.M.; Okba, N.M.A.; Fentener van Vlissingen, M.; Rockx, B.; Haagmans, B.L.; Koopmans, M.P.G.; et al. SARS-CoV-2 is transmitted via contact and via the air between ferrets. Nat. Commun. 2020, 11, 1-6. [CrossRef] [PubMed]

12. Morawska, L.; Cao, J. Airborne transmission of SARS-CoV-2: The world should face the reality. Environ. Int. 2020, 139, 105730. [CrossRef] [PubMed]

13. Wu, Y.; Guo, C.; Tang, L.; Hong, Z.; Zhou, J.; Dong, X.; Yin, H.; Xiao, Q.; Tang, Y.; Qu, X.; et al. Prolonged presence of SARS-CoV-2 viral RNA in faecal samples. Lancet Gastroenterol. Hepatol. 2020, 5, 434-435. [CrossRef]

14. Seyran, M.; Takayama, K.; Uversky, V.N.; Lundstrom, K.; Palù, G.; Sherchan, S.P.; Attrish, D.; Rezaei, N.; Aljabali, A.A.A.; Ghosh, S.; et al. The structural basis of accelerated host cell entry by SARS-CoV-2. FEBS J. 2020, 288, 5010-5020. [CrossRef]

15. Hassan, S.S.; Ghosh, S.; Attrish, D.; Choudhury, P.P.; Aljabali, A.A.A.; Uhal, B.D.; Lundstrom, K.; Rezaei, N.; Uversky, V.N.; Seyran, M.; et al. Possible Transmission Flow of SARS-CoV-2 Based on ACE2 Features. Molecules 2020, 25, 5906. [CrossRef] [PubMed]

16. Baltimore, D. Expression of animal virus genomes. Bacteriol. Rev. 1971, 35, 235-241. [CrossRef] [PubMed]

17. Zelikin, A.N.; Stellacci, F. Broad-Spectrum Antiviral Agents Based on Multivalent Inhibitors of Viral Infectivity. Adv. Healthc. Mater. 2021, 10, 2001433. [CrossRef] [PubMed]

18. Ruiz-Hitzky, E.; Darder, M.; Wicklein, B.; Ruiz-Garcia, C.; Martín-Sampedro, R.; del Real, G.; Aranda, P. Nanotechnology Responses to COVID-19. Adv. Healthc. Mater. 2020, 9, 2000979. [CrossRef] [PubMed]

19. Ho, W.; Gao, M.; Li, F.; Li, Z.; Zhang, X.Q.; Xu, X. Next-Generation Vaccines: Nanoparticle-Mediated DNA and mRNA Delivery. Adv. Healthc. Mater. 2021, 10, 2001812. [CrossRef] [PubMed]

20. Mehta, A.; Michler, T.; Merkel, O.M. siRNA Therapeutics against Respiratory Viral Infections-What Have We Learned for Potential COVID-19 Therapies? Adv. Healthc. Mater. 2021, 10, 2001650. [CrossRef]

21. Dobrowolski, C.; Paunovska, K.; Hatit, M.Z.C.; Lokugamage, M.P.; Dahlman, J.E. Therapeutic RNA Delivery for COVID and Other Diseases. Adv. Healthc. Mater. 2021, 10, 2002022. [CrossRef]

22. Vu, M.N.; Kelly, H.G.; Tan, H.X.; Juno, J.A.; Esterbauer, R.; Davis, T.P.; Truong, N.P.; Wheatley, A.K.; Kent, S.J. Hemagglutinin Functionalized Liposomal Vaccines Enhance Germinal Center and Follicular Helper T Cell Immunity. Adv. Healthc. Mater. 2021, 10, 2002142. [CrossRef]

23. Xiao, Y.; Torok, M.E. Taking the right measures to control COVID-19. Lancet Infect. Dis. 2020, 20, 523-524. [CrossRef]

24. Tuñón-Molina, A.; Takayama, K.; Redwan, E.M.; Uversky, V.N.; Andrés, J.; Serrano-Aroca, Á. Protective Face Masks: Current Status and Future Trends. ACS Appl. Mater. Interfaces 2021. [CrossRef] [PubMed]

25. Chin, A.W.H.; Chu, J.T.S.; Perera, M.R.A.; Hui, K.P.Y.; Yen, H.-L.; Chan, M.C.W.; Peiris, M.; Poon, L.L.M. Stability of SARS-CoV-2 in different environmental conditions. Lancet Microbe 2020, 1, e10. [CrossRef]

26. Martí, M.; Tuñón-Molina, A.; Aachmann, F.L.; Muramoto, Y.; Noda, T.; Takayama, K.; Serrano-Aroca, Á. Protective Face Mask Filter Capable of Inactivating SARS-CoV-2, and Methicillin-Resistant Staphylococcus aureus and Staphylococcus epidermidis. Polymers 2021, 13, 207. [CrossRef] [PubMed]

27. Tuñón-Molina, A.; Martí, M.; Muramoto, Y.; Noda, T.; Takayama, K.; Serrano-Aroca, Á. Antimicrobial Face Shield: Next Generation of Facial Protective Equipment against SARS-CoV-2 and Multidrug-Resistant Bacteria. Int. J. Mol. Sci. 2021, 22, 9518. [CrossRef]

28. Cano-Vicent, A.; Tuñón-Molina, A.; Martí, M.; Muramoto, Y.; Noda, T.; Takayama, K.; Serrano-Aroca, Á. Antiviral face mask functionalized with solidified hand soap: Low-cost infection prevention clothing against enveloped viruses such as SARS-CoV-2. ACS Omega 2021, 6, 23495-23503. [CrossRef] [PubMed]

29. Serrano-Aroca, Á.; Takayama, K.; Tuñón-Molina, A.; Seyran, M.; Hassan, S.S.; Pal Choudhury, P.; Uversky, V.N.; Lundstrom, K.; Adadi, P.; Palù, G.; et al. Carbon-Based Nanomaterials: Promising Antiviral Agents to Combat COVID-19 in the MicrobialResistant Era. ACS Nano 2021, 15, 8069-8086. [CrossRef]

30. Sanmartín-Santos, I.; Gandía-Llop, S.; Salesa, B.; Martí, M.; Lillelund Aachmann, F.; Serrano-Aroca, Á. Enhancement of Antimicrobial Activity of Alginate Films with a Low Amount of Carbon Nanofibers $(0.1 \% w / w)$. Appl. Sci. 2021, 11, 2311. [CrossRef]

31. Serrano-Aroca, Á.; Ferrandis-Montesinos, M.; Wang, R. Antiviral Properties of Alginate-Based Biomaterials: Promising Antiviral Agents against SARS-CoV-2. ACS Appl. Bio Mater. 2021, 4, 5897-5907. [CrossRef]

32. Luganini, A.; Terlizzi, M.E.; Catucci, G.; Gilardi, G.; Maffei, M.E.; Gribaudo, G. The cranberry extract oximacro®exerts in vitro virucidal activity against influenza virus by interfering with hemagglutinin. Front. Microbiol. 2018, 9, 1826. [CrossRef] [PubMed]

33. Walls, A.C.; Park, Y.J.; Tortorici, M.A.; Wall, A.; McGuire, A.T.; Veesler, D. Structure, Function, and Antigenicity of the SARS-CoV-2 Spike Glycoprotein. Cell 2020, 181, 281-292.e6. [CrossRef]

34. Su, I.C.; Lee, K.L.; Liu, H.Y.; Chuang, H.C.; Chen, L.Y.; Lee, Y.J. Severe community-acquired pneumonia due to Pseudomonas aeruginosa coinfection in an influenza A(H1N1)pdm09 patient. J. Microbiol. Immunol. Infect. 2019, 52, 365-366. [CrossRef] [PubMed]

35. Chou, C.C.; Shen, C.F.; Chen, S.J.; Chen, H.M.; Wang, Y.C.; Chang, W.S.; Chang, Y.T.; Chen, W.Y.; Huang, C.Y.; Kuo, C.C.; et al. Recommendations and guidelines for the treatment of pneumonia in Taiwan. J. Microbiol. Immunol. Infect. 2019, 52, 172-199. [CrossRef] [PubMed] 
36. Lee, J.Y.; Yang, P.C.; Chang, C.; Lin, I.T.; Ko, W.C.; Cia, C.T. Community-acquired adenoviral and pneumococcal pneumonia complicated by pulmonary aspergillosis in an immunocompetent adult. J. Microbiol. Immunol. Infect. 2019, 52, 838-839. [CrossRef]

37. Albrich, W.C.; Rassouli, F.; Waldeck, F.; Berger, C.; Baty, F. Influence of Older Age and Other Risk Factors on Pneumonia Hospitalization in Switzerland in the Pneumococcal Vaccine Era. Front. Med. 2019, 6, 286. [CrossRef] [PubMed]

38. Feikin, D.R.; Schuchat, A.; Kolczak, M.; Barrett, N.L.; Harrison, L.H.; Lefkowitz, L.; McGeer, A.; Farley, M.M.; Vugia, D.J.; Lexau, C.; et al. Mortality from invasive pneumococcal pneumonia in the era of antibiotic resistance, 1995-1997. Am. J. Public Health 2000, 90, 223-229. [PubMed]

39. Huttner, B.; Cappello, B.; Cooke, G.; Gandra, S.; Harbarth, S.; Imi, M.; Loeb, M.; Mendelson, M.; Moja, L.; Pulcini, C.; et al. 2019 community-acquired pneumonia treatment guidelines: There is a need for a change toward more parsimonious antibiotic use. Am. J. Respir. Crit. Care Med. 2020, 201, 1315-1316. [CrossRef] [PubMed]

40. Howell, A.B.; Reed, J.D.; Krueger, C.G.; Winterbottom, R.; Cunningham, D.G.; Leahy, M. A-type cranberry proanthocyanidins and uropathogenic bacterial anti-adhesion activity. Phytochemistry 2005, 66, 2281-2291. [CrossRef]

41. Rane, H.S.; Bernardo, S.M.; Howell, A.B.; Lee, S.A. Cranberry-derived proanthocyanidins prevent formation of Candida albicans biofilms in artificial urine through biofilm- and adherence-specific mechanisms. J. Antimicrob. Chemother. 2014, 69, 428-436. [CrossRef] [PubMed]

42. Pan, D.; Sze, S.; Martin, C.A.; Nevill, C.R.; Minhas, J.S.; Divall, P.; Nazareth, J.; Gray, L.J.; Khunti, K.; Abrams, K.R.; et al. COVID-19 and the new variant strain in England-What are the implications for those from ethnic minority groups? EClinicalMedicine 2021, 33, 100805. [CrossRef]

43. Otto, S.P.; Day, T.; Arino, J.; Colijn, C.; Dushoff, J.; Li, M.; Mechai, S.; Van Domselaar, G.; Wu, J.; Earn, D.J.D.; et al. The origins and potential future of SARS-CoV-2 variants of concern in the evolving COVID-19 pandemic. Curr. Biol. 2021, 31, R918-R929. [CrossRef] [PubMed]

44. Singh, D.; Yi, S. V On the origin and evolution of SARS-CoV-2. Exp. Mol. Med. 2021, 53, 537-547. [CrossRef] [PubMed]

45. Sun, Z.; Ostrikov, K. (Ken) Future antiviral surfaces: Lessons from COVID-19 pandemic. Sustain. Mater. Technol. 2020, 25 , e00203.

46. Shirvanimoghaddam, K.; Akbari, M.K.; Yadav, R.; Al-Tamimi, A.K.; Naebe, M. Fight against COVID-19: The case of antiviral surfaces. APL Mater. 2021, 9, 31112. [CrossRef] [PubMed]

47. Bhuvan, K.C.; Shrestha, R.; Leggat, P.A.; Ravi Shankar, P.; Shrestha, S. Safety of air travel during the ongoing COVID-19 pandemic. Travel Med. Infect. Dis. 2021, 43, 102103. [CrossRef]

48. Mousavi, E.S.; Godri Pollitt, K.J.; Sherman, J.; Martinello, R.A. Performance analysis of portable HEPA filters and temporary plastic anterooms on the spread of surrogate coronavirus. Build. Environ. 2020, 183, 107186. [CrossRef]

49. Ilyas, S.; Srivastava, R.R.; Kim, H. Disinfection technology and strategies for COVID-19 hospital and bio-medical waste management. Sci. Total Environ. 2020, 749, 141652. [CrossRef] [PubMed]

50. MacIntyre, C.R.; Dung, T.C.; Chughtai, A.A.; Seale, H.; Rahman, B. Contamination and washing of cloth masks and risk of infection among hospital health workers in Vietnam: A post hoc analysis of a randomised controlled trial. BMJ Open 2020, 10, e042045. [CrossRef] [PubMed]

51. Aragaw, T.A. Surgical face masks as a potential source for microplastic pollution in the COVID-19 scenario. Mar. Pollut. Bull. 2020, 159, 111517. [CrossRef]

52. Rizan, C.; Reed, M.; Bhutta, M.F. Environmental impact of personal protective equipment distributed for use by health and social care services in England in the first six months of the COVID-19 pandemic. J. R. Soc. Med. 2021, 114, 250-263. [CrossRef]

53. Hiemstra, A.-F.; Rambonnet, L.; Gravendeel, B.; Schilthuizen, M. The effects of COVID-19 litter on animal life. Anim. Biol. 2021, 71, 215-231. [CrossRef]

54. Selvaranjan, K.; Navaratnam, S.; Rajeev, P.; Ravintherakumaran, N. Environmental challenges induced by extensive use of face masks during COVID-19: A review and potential solutions. Environ. Chall. 2021, 3, 100039. [CrossRef]

55. Tuñón-Molina, A.; Cano-Vicent, A.; Martí, M.; Muramoto, Y.; Noda, T.; Takayama, K.; Serrano-Aroca, Á. Next generation infection prevention clothing: Non-woven Fabrics Coated with Cranberry Extracts Capable of Inactivating Enveloped Viruses such as SARS-CoV-2 and Multidrug-resistant Bacteria. bioRxiv 2021, 6, 23495-23503.

56. Lotfi, M.; Hamblin, M.R.; Rezaei, N. COVID-19: Transmission, prevention, and potential therapeutic opportunities. Clin. Chim. Acta 2020, 508, 254-266. [CrossRef]

57. De Georgeo, M.R.; De Georgeo, J.M.; Egan, T.M.; Klee, K.P.; Schwemm, M.S.; Bye-Kollbaum, H.; Kinser, A.J. Containing SARSCoV-2 in hospitals facing finite PPE, limited testing, and physical space variability: Navigating resource constrained enhanced traffic control bundling. J. Microbiol. Immunol. Infect. 2020, 54, 4-11. [CrossRef] [PubMed]

58. Arjunan, A.; Zahid, S.; Baroutaji, A.; Robinson, J. 3D printed auxetic nasopharyngeal swabs for COVID-19 sample collection. J. Mech. Behav. Biomed. Mater. 2020, 114, 104175. [CrossRef]

59. Pradhan, D.; Biswasroy, P.; Kumar Naik, P.; Ghosh, G.; Rath, G. A Review of Current Interventions for COVID-19 Prevention. Arch. Med. Res. 2020, 51, 363-374. [CrossRef] [PubMed]

60. Robinson, J.; Arjunan, A.; Baroutaji, A.; Martí, M.; Tuñón Molina, A.; Serrano-Aroca, Á.; Pollard, A. Additive manufacturing of anti-SARS-CoV-2 Copper-Tungsten-Silver alloy. Rapid Prototyp. J. 2021. ahead-of-print. [CrossRef]

61. Vance, A.; Bari, K.; Arjunan, A. Compressive performance of an arbitrary stiffness matched anatomical Ti64 implant manufactured using Direct Metal Laser Sintering. Mater. Des. 2018, 160, 1281-1294. [CrossRef] 
62. Phillips, W.; Medcalf, N.; Dalgarno, K.; Makatsoris, H.; Sharples, S.; Srai, J.; Hourd, P.; Kapletia, D. Redistributed Manufacturing in Healthcare Creating New Value through Disruptive Innovation; UWE Bristol: Bristol, UK, 2018.

63. Phillips, W.; Kapletia, D.; Dalgarno, K.; Hunt, P.; Bibb, R.; Makatsoris, H.; Rafiq, Q.; Roscoe, S.; Omar, B.; Willoughby, N.; et al. Innovation in healthcare manufacturing: Transforming Deployed Medical Care. In Proceedings of the The ISPIM Innovation ConferenceInnovating Our Common Future, Berlin, Germany, 23-28 June 2020; Loughborough University: Berlin, Germany, 2020.

64. Cano-Vicent, A.; Tambuwala, M.M.; Hassan, S.S.; Barh, D.; Aljabali, A.A.A.; Birkett, M.; Arjunan, A.; Serrano-Aroca, Á. Fused deposition modelling: Current status, methodology, applications and future prospects. Addit. Manuf. 2021, 47, 102378. [CrossRef]

65. Radfar, P.; Bazaz, S.R.; Mirakhorli, F.; Warkiani, M.E. The role of 3D printing in the fight against COVID-19 outbreak. J. 3D Print. Med. 2021, 5, 51-60. [CrossRef]

66. Longhitano, G.A.; Nunes, G.B.; Candido, G.; da Silva, J.V.L. The role of 3D printing during COVID-19 pandemic: A review. Prog. Addit. Manuf. 2020, 6, 1-19. [CrossRef]

67. Vakharia, V.N.; Khan, S.; Marathe, K.; Giannis, T.; Webber, L.; Choi, D. Printing in a Pandemic: 3D printing solutions for healthcare during COVID-19. A Protocol for a PRISMA systematic review. Ann. 3D Print. Med. 2021, 2, 100015. [CrossRef]

68. Jeyachandran, P.; Bontha, S.; Bodhak, S.; Balla, V.K.; Kundu, B.; Doddamani, M. Mechanical behaviour of additively manufactured bioactive glass/high density polyethylene composites. J. Mech. Behav. Biomed. Mater. 2020, 108, 103830. [CrossRef] [PubMed]

69. Zanocco, M.; Boschetto, F.; Zhu, W.; Marin, E.; McEntire, B.J.; Bal, B.S.; Adachi, T.; Yamamoto, T.; Kanamura, N.; Ohgitani, E.; et al. 3D-additive deposition of an antibacterial and osteogenic silicon nitride coating on orthopaedic titanium substrate. J. Mech. Behav. Biomed. Mater. 2020, 103, 103557. [CrossRef] [PubMed]

70. Calignano, F. Investigation of the accuracy and roughness in the laser powder bed fusion process. Virtual Phys. Prototyp. 2018, 13, 97-104. [CrossRef]

71. van Doremalen, N.; Bushmaker, T.; Morris, D.H.; Holbrook, M.G.; Gamble, A.; Williamson, B.N.; Tamin, A.; Harcourt, J.L.; Thornburg, N.J.; Gerber, S.I.; et al. Aerosol and Surface Stability of SARS-CoV-2 as Compared with SARS-CoV-1. N. Engl. J. Med. 2020, 382, 1564-1567. [CrossRef]

72. Dev Kumar, G.; Mishra, A.; Dunn, L.; Townsend, A.; Oguadinma, I.C.; Bright, K.R.; Gerba, C.P. Biocides and Novel Antimicrobial Agents for the Mitigation of Coronaviruses. Front. Microbiol. 2020, 11, 1351. [CrossRef]

73. Cortes, A.A.; Zuñiga, J.M. The use of copper to help prevent transmission of SARS-Coronavirus and Influenza viruses. A general Review. Diagn. Microbiol. Infect. Dis. 2020, 98, 115176. [CrossRef]

74. Pullangott, G.; Kannan, U.; Gayathri, S.; Kiran, D.V.; Maliyekkal, S.M. A comprehensive review on antimicrobial face masks: An emerging weapon in fighting pandemics. RSC Adv. 2021, 11, 6544-6576. [CrossRef]

75. Duan, S.-M.; Zhao, X.-S.; Wen, R.-F.; Huang, J.-J.; Pi, G.-H.; Zhang, S.-X.; Han, J.; Bi, S.-L.; Ruan, L.; Dong, X.-P. Stability of SARS coronavirus in human specimens and environment and its sensitivity to heating and UV irradiation. Biomed. Environ. Sci. 2003, 16, 246-255. [PubMed]

76. Chan, K.H.; Peiris, J.S.M.; Lam, S.Y.; Poon, L.L.M.; Yuen, K.Y.; Seto, W.H. The effects of temperature and relative humidity on the viability of the SARS coronavirus. Adv. Virol. 2011, 2011, 734690. [CrossRef] [PubMed]

77. Rabenau, H.F.; Cinatl, J.; Morgenstern, B.; Bauer, G.; Preiser, W.; Doerr, H.W. Stability and inactivation of SARS coronavirus. Med. Microbiol. Immunol. 2005, 194, 1-6. [CrossRef]

78. Lai, M.Y.Y.; Cheng, P.K.C.; Lim, W.W.L. Survival of Severe Acute Respiratory Syndrome Coronavirus. Clin. Infect. Dis. 2005, 41, e67-e71. [CrossRef] [PubMed]

79. Kampf, G.; Todt, D.; Pfaender, S.; Steinmann, E. Persistence of coronaviruses on inanimate surfaces and their inactivation with biocidal agents. J. Hosp. Infect. 2020, 104, 246-251. [CrossRef]

80. Aydogdu, M.O.; Altun, E.; Chung, E.; Ren, G.; Homer-Vanniasinkam, S.; Chen, B.; Edirisinghe, M. Surface interactions and viability of coronaviruses. J. R. Soc. Interface 2021, 18, 20200798. [CrossRef] [PubMed]

81. Shidham, V.B.; Frisch, N.K.; Layfield, L.J. Severe acute respiratory syndrome coronavirus 2 (the cause of COVID 19) in different types of clinical specimens and implications for cytopathology specimen: An editorial review with recommendations. Cytojournal 2020, 17, 7. [CrossRef]

82. Hutasoit, N.; Kennedy, B.; Hamilton, S.; Luttick, A.; Rahman Rashid, R.A.; Palanisamy, S. Sars-CoV-2 (COVID-19) inactivation capability of copper-coated touch surface fabricated by cold-spray technology. Manuf. Lett. 2020, 25, 93-97. [CrossRef]

83. Balagna, C.; Perero, S.; Percivalle, E.; Nepita, E.V.; Ferraris, M. Virucidal effect against coronavirus SARS-CoV-2 of a silver nanocluster/silica composite sputtered coating. Open Ceram. 2020, 1, 100006. [CrossRef]

84. Bradley, D. Copper against Covid. Mater. Today 2020, $x x, 7021$. [CrossRef]

85. Hatamie, S.; Nouri, M.; Karandikar, S.K.; Kulkarni, A.; Dhole, S.D.; Phase, D.M.; Kale, S.N. Complexes of cobalt nanoparticles and polyfunctional curcumin as antimicrobial agents. Mater. Sci. Eng. C 2012, 32, 92-97. [CrossRef]

86. Chang, E.L.; Simmers, C.; Knight, D.A. Cobalt Complexes as Antiviral and Antibacterial Agents. Pharmaceuticals 2010, 3 , 1711-1728. [CrossRef]

87. Watanabe, K.; Fukuzaki, S.; Sugino, A.; Benson, N.; Metcalf, N.; Nakamura, M.; Matsumoto, M. Cobalt-Chromium Alloy has Superior Antibacterial Effect than Titanium Alloy: In Vitro: And: In Vivo: Studies. Spine 2021, 46, E911. [CrossRef]

88. Zhukov, A.S.; Barakhtin, B.K.; Kamynin, A.V.; Gavrikov, I.S.; Kuznetsov, P.A. Features of structure-sensitive hard magnetic alloy $\mathrm{Fe}-25$ wt. \% Cr-15 wt. \% Co manufactured by Laser Powder Bed Fusion. Procedia CIRP 2020, 94, 243-247. [CrossRef] 
89. Santecchia, E.; Gatto, A.; Bassoli, E.; Denti, L.; Rutkowski, B.; Mengucci, P.; Barucca, G. Precipitates formation and evolution in a Co-based alloy produced by powder bed fusion. J. Alloys Compd. 2019, 797, 652-658. [CrossRef]

90. Priya, P.; Mercer, B.; Huang, S.; Aboukhatwa, M.; Yuan, L.; Chaudhuri, S. Towards prediction of microstructure during laser based additive manufacturing process of Co-Cr-Mo powder beds. Mater. Des. 2020, 196, 109117. [CrossRef]

91. Young, Z.A.; Guo, Q.; Parab, N.D.; Zhao, C.; Qu, M.; Escano, L.I.; Fezzaa, K.; Everhart, W.; Sun, T.; Chen, L. Types of spatter and their features and formation mechanisms in laser powder bed fusion additive manufacturing process. Addit. Manuf. 2020, 36, 101438. [CrossRef]

92. Konieczny, B.; Szczesio-Wlodarczyk, A.; Sokolowski, J.; Bociong, K. Challenges of Co-Cr Alloy Additive Manufacturing Methods in Dentistry-The Current State of Knowledge (Systematic Review). Materials 2020, 13, 3524. [CrossRef]

93. Mukherjee, T.; DebRoy, T. Mitigation of lack of fusion defects in powder bed fusion additive manufacturing. J. Manuf. Process. 2018, 36, 442-449. [CrossRef]

94. Darvish, K.; Chen, Z.W.; Pasang, T. Reducing lack of fusion during selective laser melting of CoCrMo alloy: Effect of laser power on geometrical features of tracks. Mater. Des. 2016, 112, 357-366. [CrossRef]

95. Arjunan, A.; Singh, M.; Baroutaji, A.; Wang, C. Additively manufactured AlSi10Mg inherently stable thin and thick-walled lattice with negative Poisson's ratio. Compos. Struct. 2020, 247, 112469. [CrossRef]

96. Yadroitsev, I.; Yadroitsava, I.; Du Plessis, A.; MacDonald, E. (Eds.) Fundamentals of Laser Powder Bed Fusion of Metals, 1st ed.; Elsevier: Amsterdam, The Netherlands, 2021; ISBN 9780128240908.

97. Khairallah, S.A.; Anderson, A.T.; Rubenchik, A.; King, W.E. Laser powder-bed fusion additive manufacturing: Physics of complex melt flow and formation mechanisms of pores, spatter, and denudation zones. Acta Mater. 2016, 108, 36-45. [CrossRef]

98. Zhang, T.; Li, H.; Liu, S.; Shen, S.; Xie, H.; Shi, W.; Zhang, G.; Shen, B.; Chen, L.; Xiao, B.; et al. Evolution of molten pool during selective laser melting of Ti-6Al-4V. J. Phys. D. Appl. Phys. 2018, 52, 55302. [CrossRef]

99. Sun, Z.; Tan, X.; Tor, S.B.; Yeong, W.Y. Selective laser melting of stainless steel 316L with low porosity and high build rates. Mater. Des. 2016, 104, 197-204. [CrossRef]

100. Tucho, W.M.; Lysne, V.H.; Austbø, H.; Sjolyst-Kverneland, A.; Hansen, V. Investigation of effects of process parameters on microstructure and hardness of SLM manufactured SS316L. J. Alloys Compd. 2018, 740, 910-925. [CrossRef]

101. Song, C.; Zhang, M.; Yang, Y.; Wang, D.; Jia-kuo, Y. Morphology and properties of CoCrMo parts fabricated by selective laser melting. Mater. Sci. Eng. A 2018, 713, 206-213. [CrossRef]

102. Bayat, M.; Thanki, A.; Mohanty, S.; Witvrouw, A.; Yang, S.; Thorborg, J.; Skat Tiedje, N.; Hattel, J.H. Keyhole-induced porosities in Laser-based Powder Bed Fusion (L-PBF) of Ti6Al4V: High-fidelity modelling and experimental validation. Addit. Manuf. 2019, 30, 100835. [CrossRef]

103. King, W.E.; Barth, H.D.; Castillo, V.M.; Gallegos, G.F.; Gibbs, J.W.; Hahn, D.E.; Kamath, C.; Rubenchik, A.M. Observation of keyhole-mode laser melting in laser powder-bed fusion additive manufacturing. J. Mater. Process. Technol. 2014, 214, 2915-2925. [CrossRef]

104. Robinson, J.; Arjunan, A.; Stanford, M.; Lyall, I.; Williams, C. Effect of silver addition in copper-silver alloys fabricated by laser powder bed fusion in situ alloying. J. Alloys Compd. 2021, 857, 157561. [CrossRef]

105. Bryant, C.; Wilks, S.A.; Keevil, C.W. Rapid inactivation of SARS-CoV-2 on copper touch surfaces determined using a cell culture infectivity assay. bioRxiv 2021. [CrossRef]

106. Arjunan, A.; Robinson, J.; Al Ani, E.; Heaselgrave, W.; Baroutaji, A.; Wang, C. Mechanical performance of additively manufactured pure silver antibacterial bone scaffolds. J. Mech. Behav. Biomed. Mater. 2020, 112, 104090. [CrossRef]

107. Kitajima, M.; Ahmed, W.; Bibby, K.; Carducci, A.; Gerba, C.P.; Hamilton, K.A.; Haramoto, E.; Rose, J.B. SARS-CoV-2 in wastewater: State of the knowledge and research needs. Sci. Total Environ. 2020, 739, 139076. [CrossRef]

108. Fedorenko, A.; Grinberg, M.; Orevi, T.; Kashtan, N. Survival of the enveloped bacteriophage Phi6 (a surrogate for SARS-CoV-2) in evaporated saliva microdroplets deposited on glass surfaces. Sci. Rep. 2020, 10, 22419. [CrossRef] 